Supporting Information

\title{
Highly Efficient and Selective Generation of Ammonia and Hydrogen on a Graphdiyne-Based Catalyst
}

Lan Hui, ${ }^{\dagger}$ Yurui Xue,,${ }^{*}$ Huidi Yu,${ }^{\dagger}$ Yuxin Liu,${ }^{\dagger}$ Yan Fang, ${ }^{\dagger}$ Chengyu Xing, ${ }^{\dagger}$ Bolong Huang, ${ }^{\dagger}$ and Yuliang $\mathrm{Li}^{*}, \dagger, \S$

†Institute of Chemistry, Chinese Academy of Sciences, Beijing 100190, People's Republic of China.

Department of Applied Biology and Chemical Technology, The Hong Kong Polytechnic University, Hung Hom, Kowloon, Hong Kong SAR, China.

${ }^{\S}$ University of Chinese Academy of Sciences, Beijing 100049, People’s Republic of China. 


\section{Materials}

Tetrabutylammonium fluoride (TBAF) was purchased from Alfa Aesar. Hexabromobenzene was brought from J\&K Scientific. Toluene and tetrahydrofuran (THF) were refluxed with sodium pieces for sufficient time in order to remove the remaining water. All other reagents were purchased from Sinopharm Chemical Reagent Co., Ltd., and used without further purification unless specifically mentioned. The water used for all experiment was purified with a Millipore system. All the chemicals were of chemical grade and were used as received without further purification.

\section{Preparation of 3D graphdiyne electrode}

GDY was synthesized using a modified Glaser-Hay coupling method. $20 \mathrm{mg}$ HEB was solved in a mixed solution of $5 \mathrm{~mL}$ pyridine, $50 \mathrm{ml}$ acetone and $1 \mathrm{~mL}$ TMEDA, and added very slowly into a three-neck flask containing $50 \mathrm{~mL}$ acetone, several pieces of $\mathrm{Cu}$ foil and carbon cloth (CC). After 2 days' reaction at $50{ }^{\circ} \mathrm{C}$ in dark, the $\mathrm{CC}$ loaded with GDY nanosheet was collected and washed with hot acetone, DMF, $\mathrm{KOH}(4 \mathrm{M}), \mathrm{HCl}(6 \mathrm{M}), \mathrm{KOH}(4 \mathrm{M})$ and deionized water sequentially. After that, the cleaned sample was dried in a $40{ }^{\circ} \mathrm{C}$ vacuum oven for $12 \mathrm{~h}$.

\section{Preparation of $\mathrm{Mo}^{0} / \mathrm{GDY}$}

$\mathrm{Mo}^{0} / \mathrm{GDY}$ was prepared using a solvothermal reduction method. Briefly, $20 \mathrm{mg} \mathrm{Na} 2 \mathrm{MoO}_{4}$ was solved in $20 \mathrm{~mL}$ Ar-degassed aqueous solution and stirred for $5 \mathrm{~h}$ and then transferred into a Teflon-lined stainless steel autoclave containing a piece of as-prepared GDY. After $12 \mathrm{~h}$ reaction at $120^{\circ} \mathrm{C}$, the prepared $\mathrm{Mo}^{0} / \mathrm{GDY}$ was obtained and washed with Ar-degassed deionized water and used for electrochemical tests immediately.

\section{Calculation setup}

Density functional theory (DFT) calculations have been performed based on the CASTEP code. ${ }^{1}$ For the electronic orbital decompositions, the related calculations are carried out by recently developed ab-initio orbital self-energy minimization technique. ${ }^{2}$ This method provides the detail of the selfconsistent determination process for the orbital parameters with best matching the specific chemical bonding environment of the given solid materials systems. Related coding technique has been compiled within the simple rotationally invariant DFT $+\mathrm{U}$ framework imbedded within the CASTEP source code. ${ }^{3}$ The optimization on the structural configuration of GDY-Mo system has been self- 
consistently performed based on the Broyden-Fletcher-Goldfarb-Shannon (BFGS) algorithm. The PBE functional is chosen and related plane wave basis set cut-off energy is set at the $750 \mathrm{eV}$ based on a Monkhost-Pack k-point mesh of $4 \times 4 \times 2$. The ensemble DFT (EDFT) has been used for improving the electronic minimization to overcome the spurious spin-charge perturbation seen in density-mixing scheme $^{4}$. The convergence tolerance of total energy calculation is determined at $5.0 \times 10^{-7} \mathrm{eV} /$ atom with ionic force minimization level of $0.001 \mathrm{eV} / \AA$ by Hellmann-Feynman theorem.

The Mo, C, N, and $\mathrm{H}$ norm-conserving pseudopotentials are generated using the OPIUM code in the Kleinman-Bylander projector form, ${ }^{5}$ and the non-linear partial core correction for the Mo valence electrons $^{6}$ and a scalar relativistic averaging scheme ${ }^{7}$ are selected to treat the spin-orbital coupling effect. We chose the $(4 d, 5 s, 5 p),(2 s, 2 p),(1 \mathrm{~s})$ states as the valence states of Mo, C, N, and $\mathrm{H}$ atoms respectively. The RRKJ method is chosen for the optimization of the pseudopotentials. ${ }^{8}$ The Hubbard $\mathrm{U}$ parameters on the Mo-4d orbitals is self-consistently to be $\mathrm{U}_{\mathrm{d}}=5.79 \mathrm{eV}$.

\section{Characterizations}

TEM/HRTEM and SEM images were recorded using a JEM-2100F electron microscope operating at $200 \mathrm{kV}$ and an S-4800 field emission scanning electron microscope, respectively. XRD measurements were conducted on a $\mathrm{D} / \mathrm{max}-2500$ rotation anode X-ray diffractometer (Rigaku, Japan) with $\mathrm{Cu} \mathrm{K} \alpha$ radiation $(\lambda=1.54178 \AA)$. XPS measurements were collected form a Thermo Scientific ESCALab 250Xi instrument with monochromatic Al Ka X-ray radiation. HAADF-STEM images were collected on an aberration-corrected cubed FET Titan Cubed Themis G2 300 or JEM-ARM200F (JEOL, Tokyo, Japan). Raman spectra of the samples were measured through the Renishaw-2000 Raman spectrometer (473 nm excitation laser source).

\section{Electrochemical measurements}

All electrochemical measurements were conducted through an electrochemical workstation (CHI 660E). The H-type electrolyte cell separated by the pre-treated Nafion 117 membrane was used as the electrochemical reactor. Working electrodes were placed directly on the cathodic chamber, and the counter electrode (graphite rod) and reference electrode (saturated 
calomel electrode) were placed on the anodic chamber. For ECNRR, $30 \mathrm{~mL} \mathrm{~N}_{2}$-saturated 0.1 $\mathrm{M} \mathrm{Na}_{2} \mathrm{SO}_{4} / 0.1 \mathrm{M} \mathrm{HCl}$ was used as electrolyte. During the ECNRR process, continuous $\mathrm{N}_{2}$ were supplied into the electrolyte. For HER, all the electrochemical measurements were conducted in $\mathrm{H}_{2}$-satarated $0.5 \mathrm{M} \mathrm{H}_{2} \mathrm{SO}_{4}$.

\section{$\mathrm{NH}_{3}$ determination}

The standard curves were calibrated in each condition to determine the concentration of $\mathrm{NH}_{3}$. In $0.1 \mathrm{M} \mathrm{Na}_{2} \mathrm{SO}_{4}$ solution, a spectrophotometry method was employed to detect the resulted $\mathrm{NH}_{3}$. Briefly, $50 \mu \mathrm{L}$ oxidizing solution [a mixture of $\mathrm{NaClO}(\rho \mathrm{Cl}=4 \sim 4.9)$ and $0.75 \mathrm{M} \mathrm{NaOH}$, $500 \mu \mathrm{L}$ coloring solution (a mixture of $0.4 \mathrm{M} \mathrm{C}_{7} \mathrm{H}_{5} \mathrm{O}_{3} \mathrm{Na}$ and $0.32 \mathrm{M} \mathrm{NaOH}$ ) and $50 \mu \mathrm{L}$ $\mathrm{Na}_{2}\left[\mathrm{Fe}(\mathrm{CN})_{5} \mathrm{NO}\right] \cdot 2 \mathrm{H}_{2} \mathrm{O}\left(1.0\right.$ wt.\%) were added into standard $\mathrm{NH}_{4} \mathrm{Cl}$ solution (4 mL) with series concentration. A UV-Vis absorption measurements were conducted after $1 \mathrm{~h}$. For each standard solution, the absorbance at the wavelength of $660 \mathrm{~nm}$ was plotted against $\mathrm{NH}_{4} \mathrm{Cl}$ concentration. The calibration curve showed good linear relationship $(y=2.1189 x-0.0216$, $\left.\mathrm{R}^{2}=0.999\right)$.

In $0.1 \mathrm{M} \mathrm{HCl}, \mathrm{NH}_{3}$ was qualified exploiting an indophenol method. Typically, $2 \mathrm{~mL}$ color solution (5\% salicylic acid and 5\% sodium citrate in $1 \mathrm{M} \mathrm{NaOH}), 1 \mathrm{~mL}$ oxidizing solution $(0.05 \mathrm{NaClO})$, and $200 \mu \mathrm{L}$ catalysts solution $\left(1 \mathrm{wt} . \% \mathrm{Na}_{2}\left[\mathrm{Fe}(\mathrm{CN})_{5} \mathrm{NO}\right] \cdot 2 \mathrm{H}_{2} \mathrm{O}\right)$ were added into $2 \mathrm{~mL}$ standard $\mathrm{NH}_{4} \mathrm{Cl}$ aqueous solution with different determined concentration. The UvVis measurements were performed after $2 \mathrm{~h}$. The calibration curved was obtained from the absorptance at $655 \mathrm{~nm}$ and exhibited reliable linear relationship $(y=0.1367 x+0.0085$, $\left.\mathrm{R}^{2}=0.999\right)$.

The average $\mathrm{NH}_{3}$ yield $\left(\mathrm{Y}_{\mathrm{NH}}\right)$ can be calculated using the following equation: 
$Y_{N H 3}=\frac{0.318 \times C_{N H 4 C 1} \times V}{t \times m_{c a t .}}$

where $C_{N H 4 C l}$ is the mass concentration of $\mathrm{NH}_{4} \mathrm{Cl}, V$ is volume of cathodic electrolyte, $t$ is the time for ECNRR, $m_{\text {cat. }}$ is the mass loading of the sample.

Faradic efficiency (FE) can be calculated as following:

$F E=\frac{0.954 F \times C_{N H 4 C l} \times V}{Q}$

where $F$ is Faradic Constant and Q is the electric quantity. 

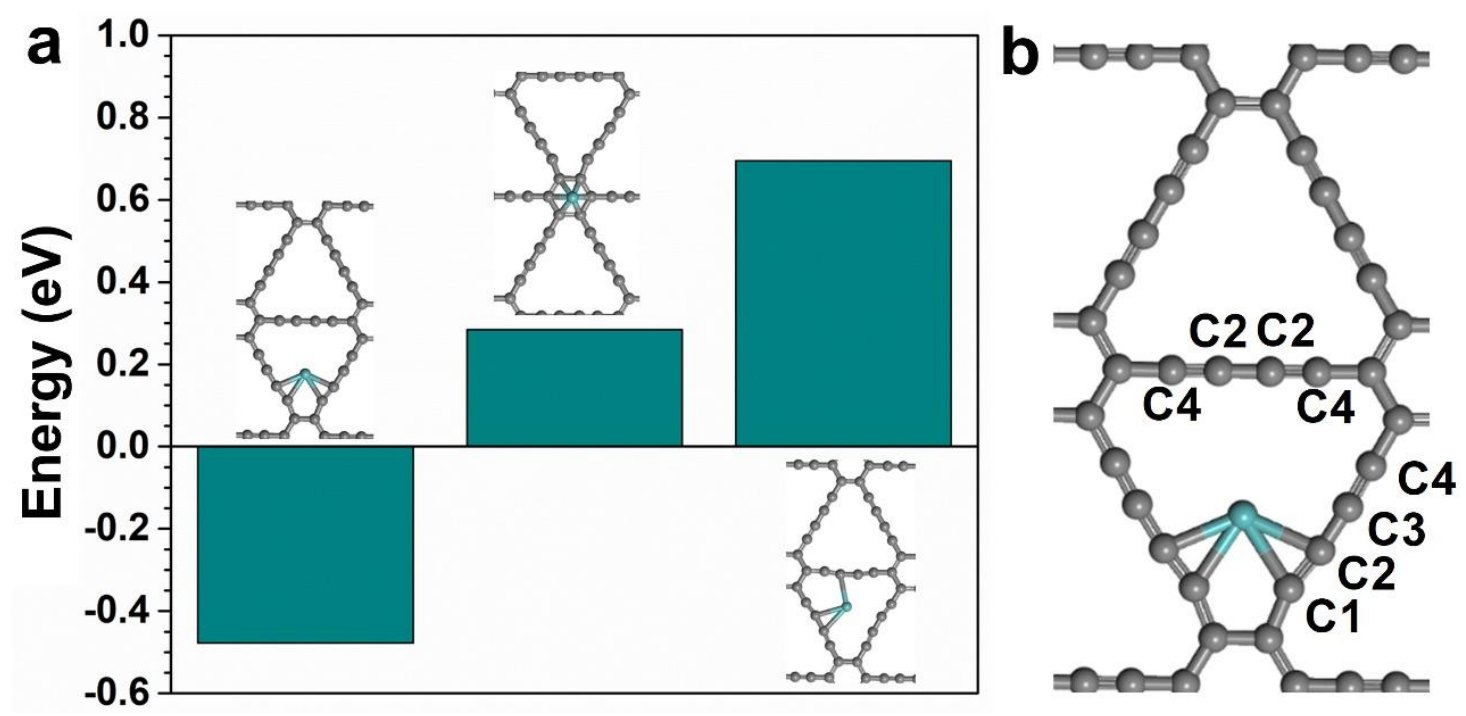

Figure S1. Structural optimization. (a) The formation energies comparison of different anchoring sites. (b) Illustration of the positions of $\mathrm{C} 1-\mathrm{C} 4$ sites.

To enrich the context of the computational models, we have supplied the additional comparison between different anchoring sites as the reliable support to our present results. The $\mathrm{C} 1-\mathrm{C} 4$ positions are shown that illustrate the different carbon sites on the carbon chain between benzene rings of GDY. The $\mathrm{C} 1$ site clearly shows the bonding and anti-bonding splitting and confirms the stable Mo-C1 interaction. We find the $\mathrm{C} 1$ and $\mathrm{C} 2$ sites possess an intermediate level of p-electron populations, which promote the electron-transfer pathway between Mo and GDY system. More importantly, the present anchoring site based on the interaction with the $\mathrm{C}-\mathrm{C}$ triple bond will require the lowest energy cost than other positions. 

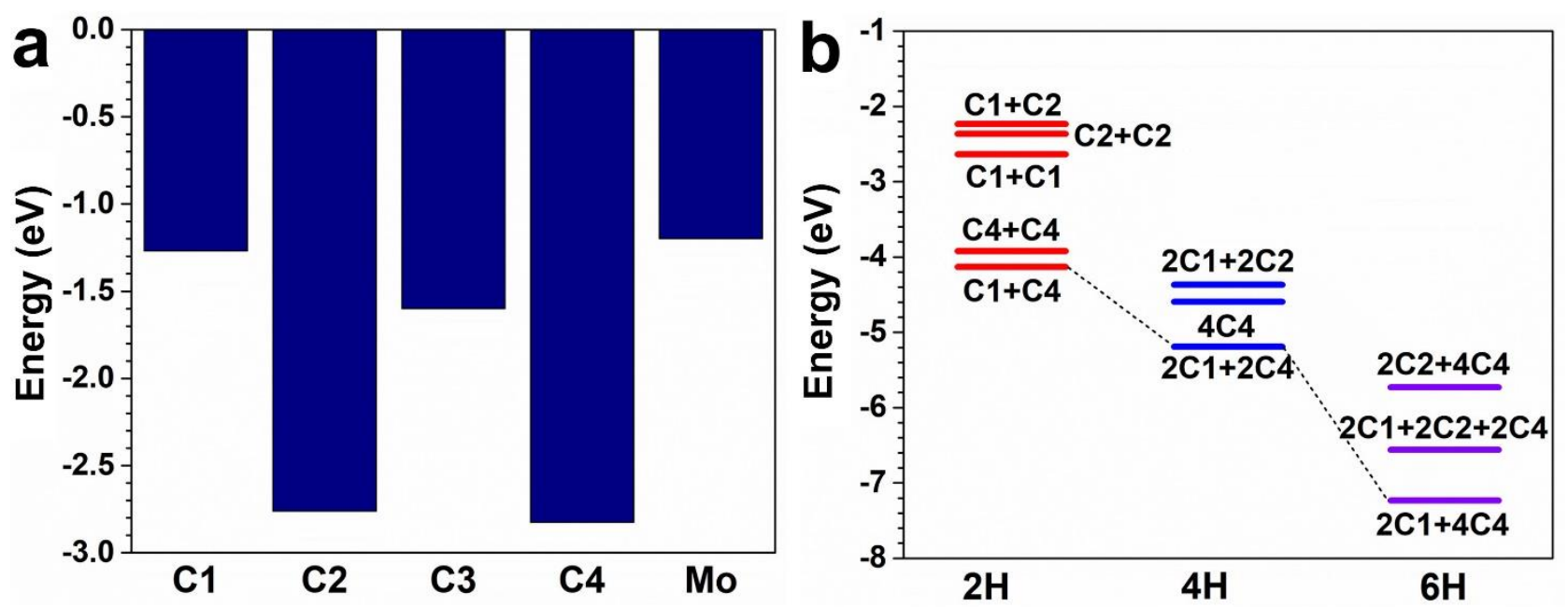

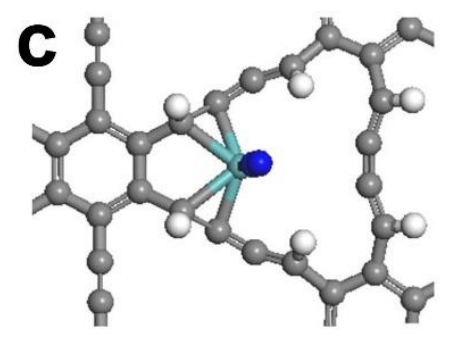

${ }^{*} \mathrm{~N} \equiv \mathrm{N}+6 \mathrm{H}$

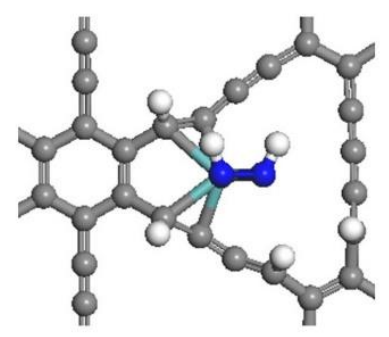

${ }^{*} \mathrm{NH}=\mathrm{NH}+\mathbf{4 H}$

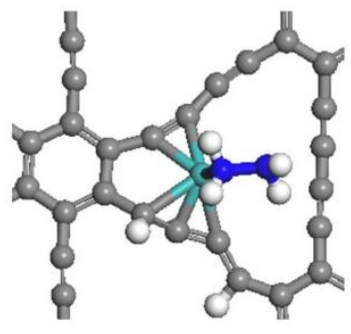

* $\mathrm{NH}_{2}-\mathrm{NH}_{2}+4 \mathrm{H}$

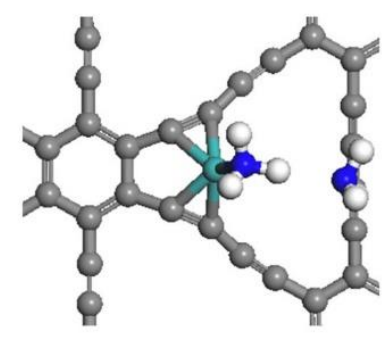

$\mathrm{NH}_{3}$

Figure S2. The structural configuration evolution of ECNRR. (a) The formation energies $\mathrm{H}$ at different sites. (b) The formation energies of structural evolution from $2 \mathrm{H}$ to $6 \mathrm{H}$. (c) Structural evolution during the ECNRR process.

Additional examinations of the varied $\mathrm{H}$ atoms have been carried out to verify the structural configuration evolution of ECNRR. Comparing with the C sites on GDY, Mo sites display much less energetic preference that supports our structural configurations with $\mathrm{H}$ adsorption on the carbon sites. The further multi-H adsorptions are also compared to verify the structures from $\mathrm{N}_{2}$ to $\mathrm{NH}_{3}$. Notably, the lowest energy structural evolution from $2 \mathrm{H}$ to $6 \mathrm{H}$ will be $\mathrm{C} 1+\mathrm{C} 4 \rightarrow 2 \mathrm{C} 1+2 \mathrm{C} 4 \rightarrow 2 \mathrm{C} 1+4 \mathrm{C} 4$, which is consistent with the presented structures in the manuscript. Moreover, a downhill trend of $\mathrm{H}$ adsorption is clearly observed, supporting the energetically favourable route from $2 \mathrm{H}$ to $6 \mathrm{H}$. 


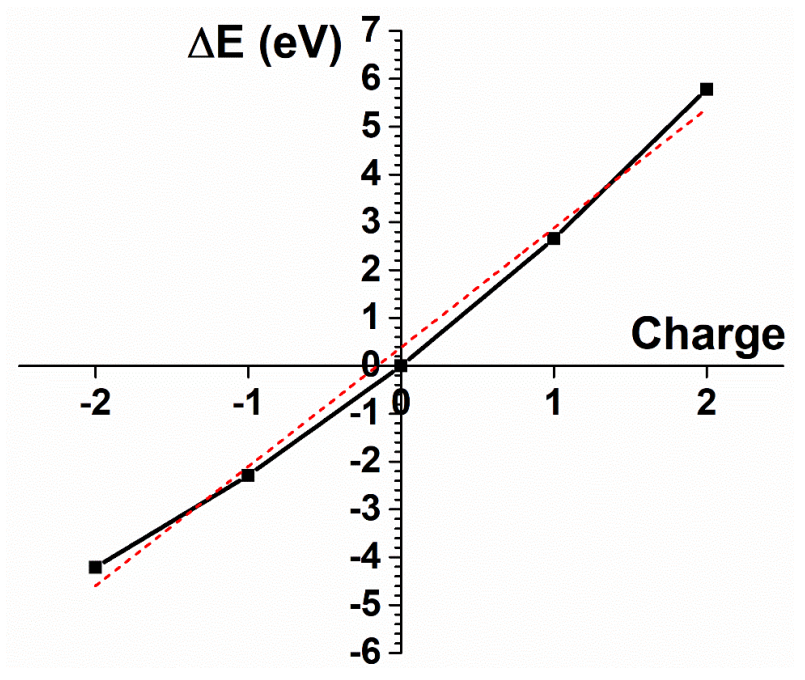

Figure S3. The electron-affinity determination of Mo on GDY.

The zero-valence of the anchoring metal is achieved by the abnormal strong $(s p)$ - $d$ overlapping, which will induce inert closed-shell effect for transition metal on GDY and lead to an extrinsic charge compensation to reduce the oxidation state of metal to the zero valence state. The extra active electrons from local GDY contribute to the electron-affinitive Mo, which breaks the constraints of electron supply to achieve the firm adsorption of $\mathrm{N}_{2}$ to initiate the ECNRR. Following the previously reported approach in calculating the orbital energy, we confirm the $\delta$ value of Mo with the electronaffinity. The intercept of the linear fitting represented the $\delta$ value of Mo will be 0.3874 . Meanwhile, the large slope of the fitting demonstrates high stability of zero-valence rather than being oxidized due to the high energy barrier of losing electrons. Therefore, here in this work, we believe that Mo will maintain the zero-valence state based on the strong interaction with the GDY substrate. 


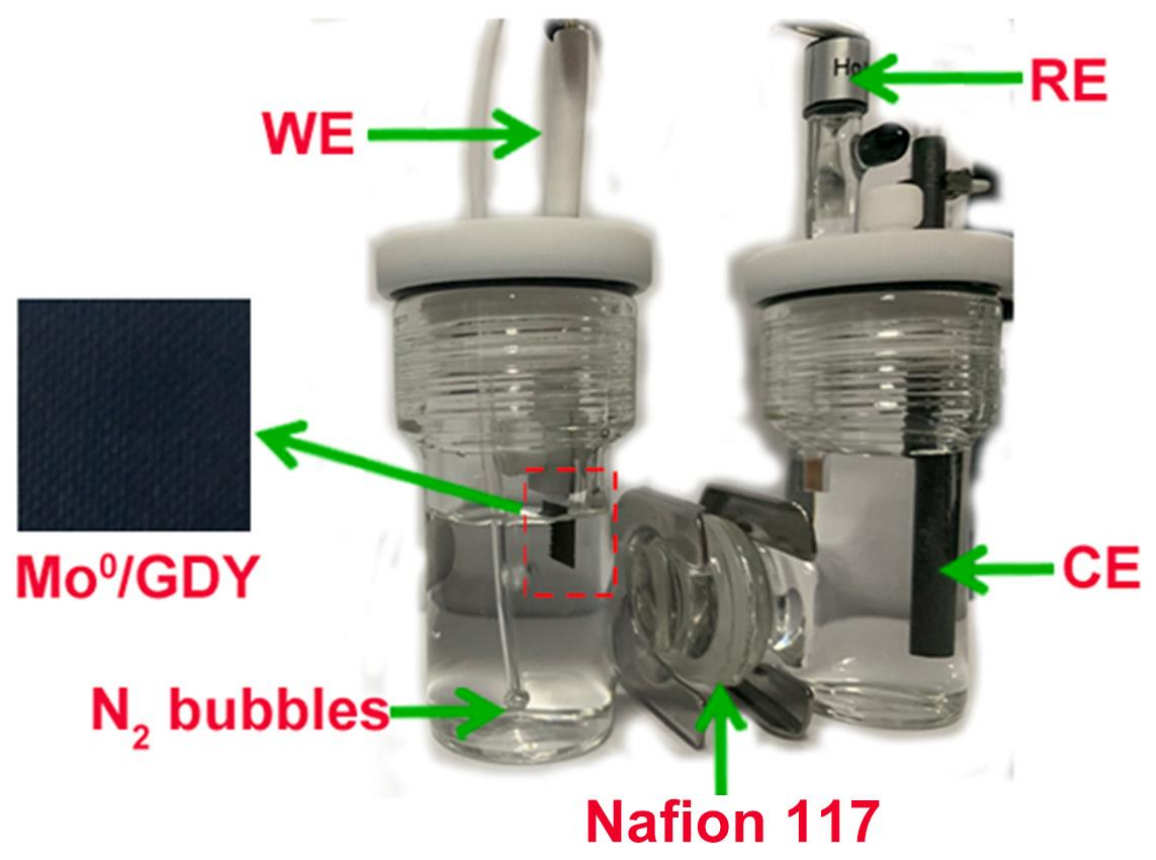

Figure S4. Optical photograph of electrolyte cell for ECNRR. 


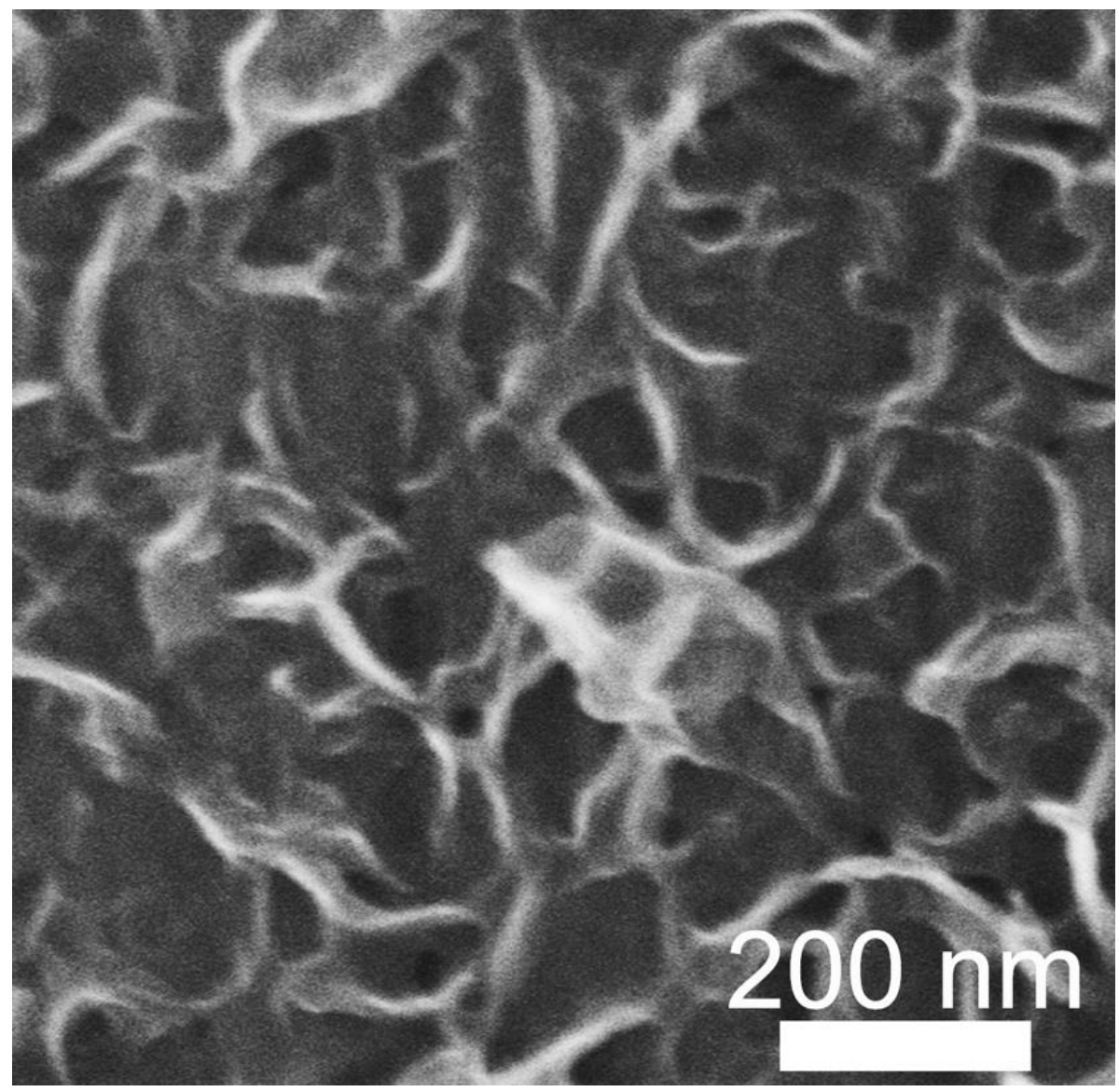

Figure S5. SEM image of Mo $\%$ GDY sample. 


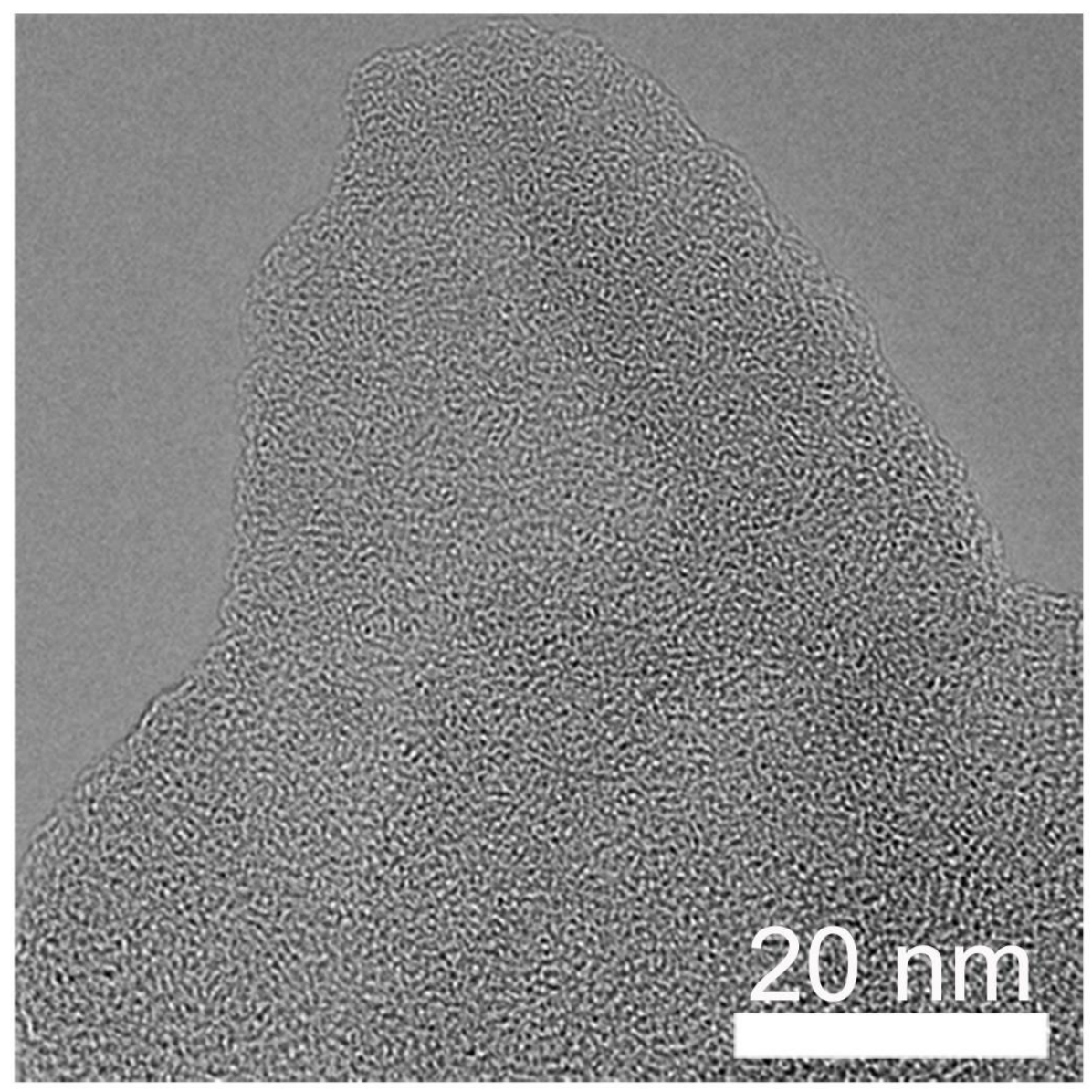

Figure S6. TEM image of $\mathrm{Mo}^{\circ} / \mathrm{GDY}$ nanosheets. 


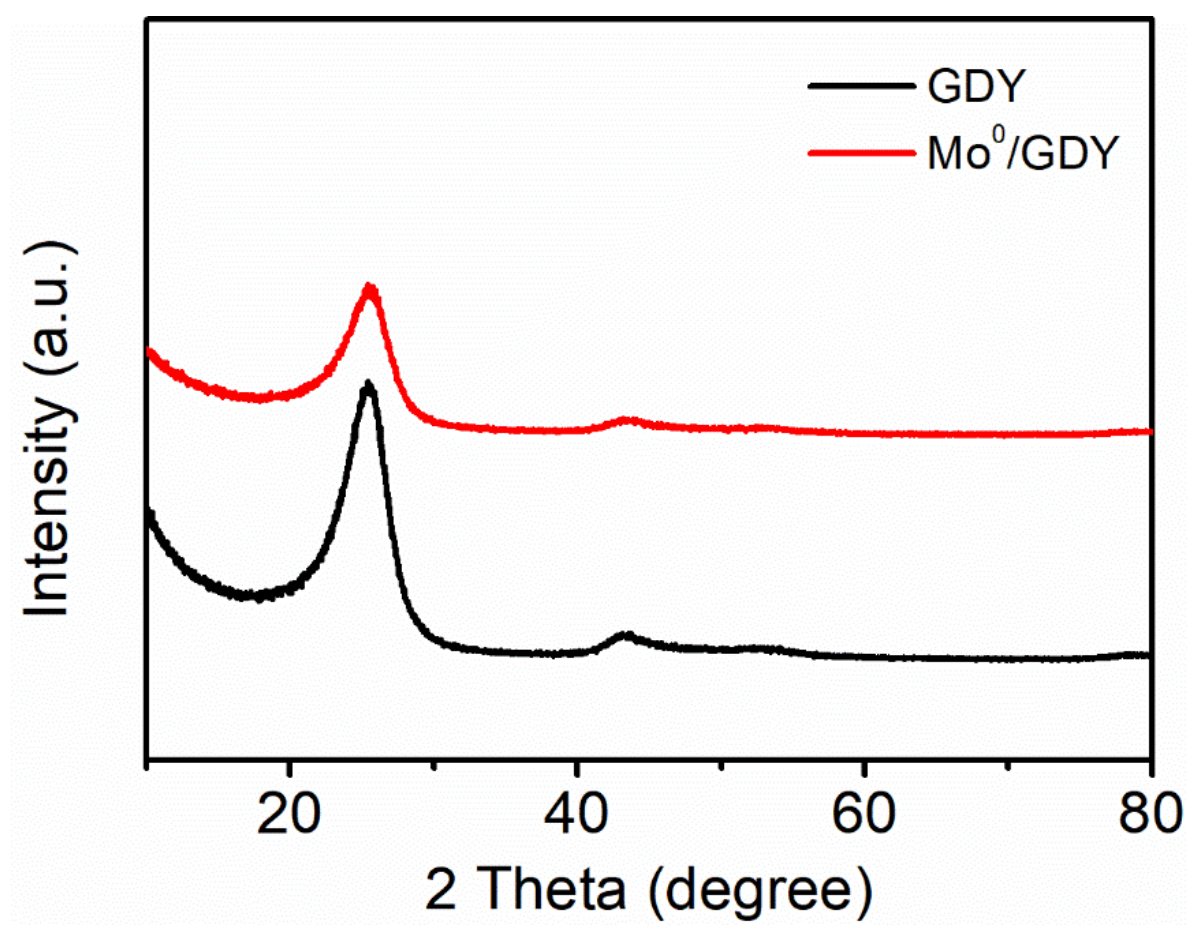

Figure S7. XRD pattern of $\mathrm{Mo}^{\circ} / \mathrm{GDY}$ and GDY. All the peaks are ascribed to carbon species for both samples. No presence of metallic Mo was detected in $\mathrm{Mo}^{\circ} / \mathrm{GDY}$. 


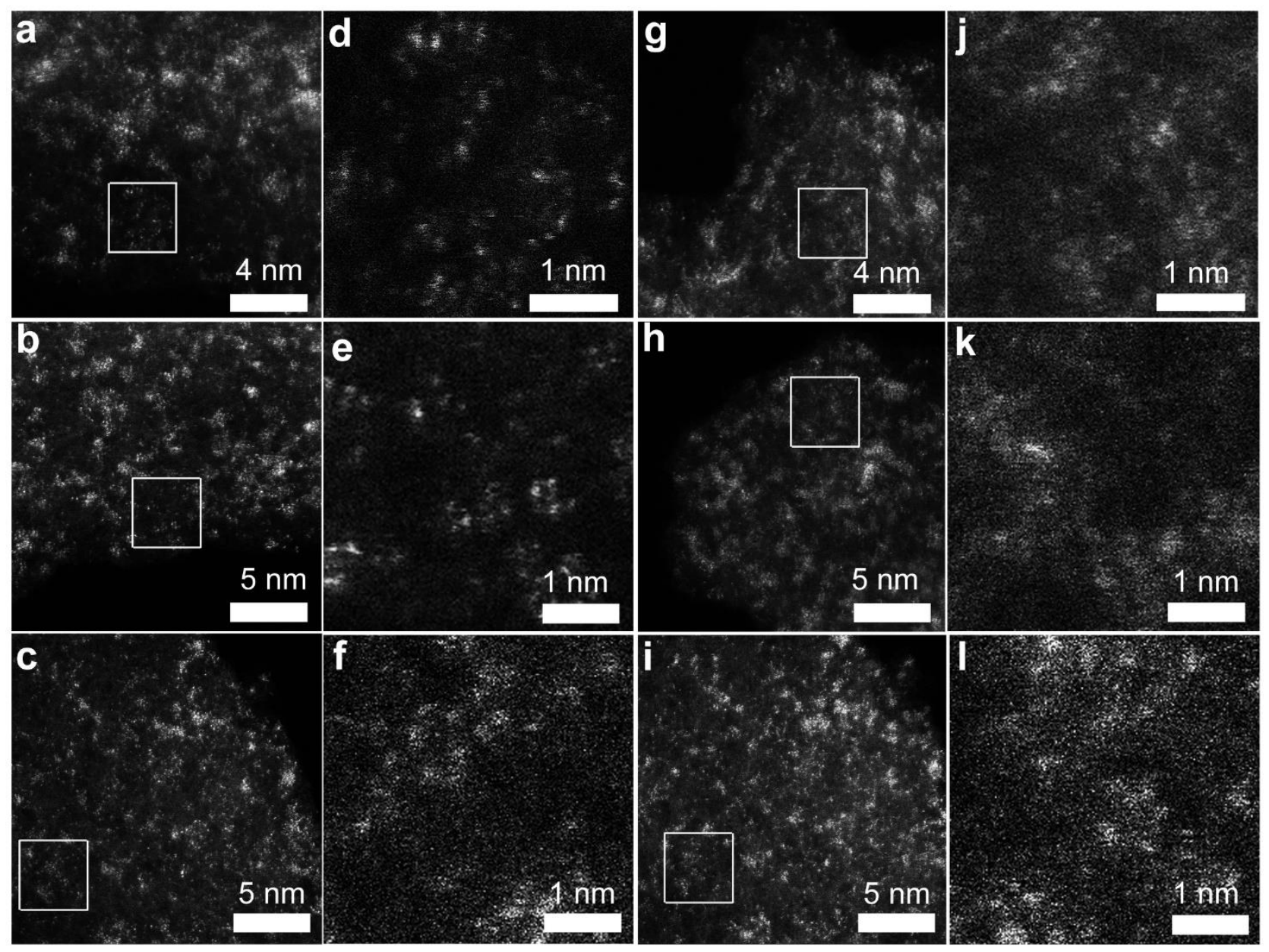

Figure S8. (a-1) HAADF images of $\mathrm{Mo}^{0} / \mathrm{GDY}$ recorded at different regions of different batches of samples. 

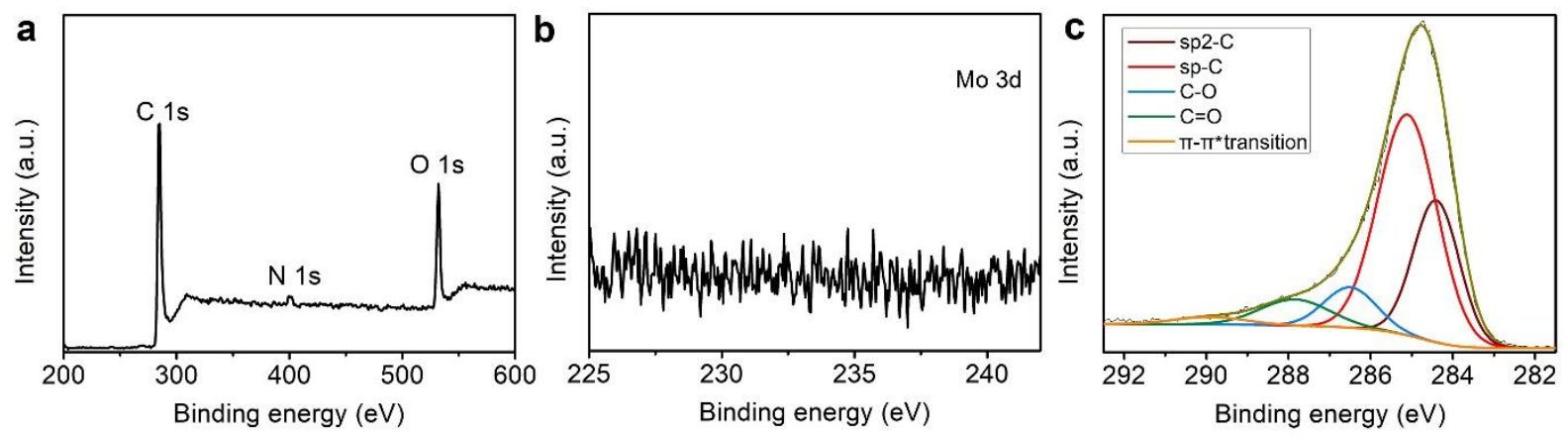

Figure S9. The survey spectrum (a) and high-resolution XPS spectra of the Mo 3d (b) and C1s (c) of the freshly-prepared $\mathrm{Mo}^{0} / \mathrm{GDY}$. The peaks in C 1s spectrum at 284.5, 285.2, 286.5, 288.0 and 290.0 $\mathrm{eV}$ corresponds to the $\mathrm{sp}^{2}-\mathrm{C}, \mathrm{sp}-\mathrm{C}, \mathrm{C}=\mathrm{O}, \mathrm{C}=\mathrm{O}$ and $\pi-\pi^{*}$ transition, respectively. 


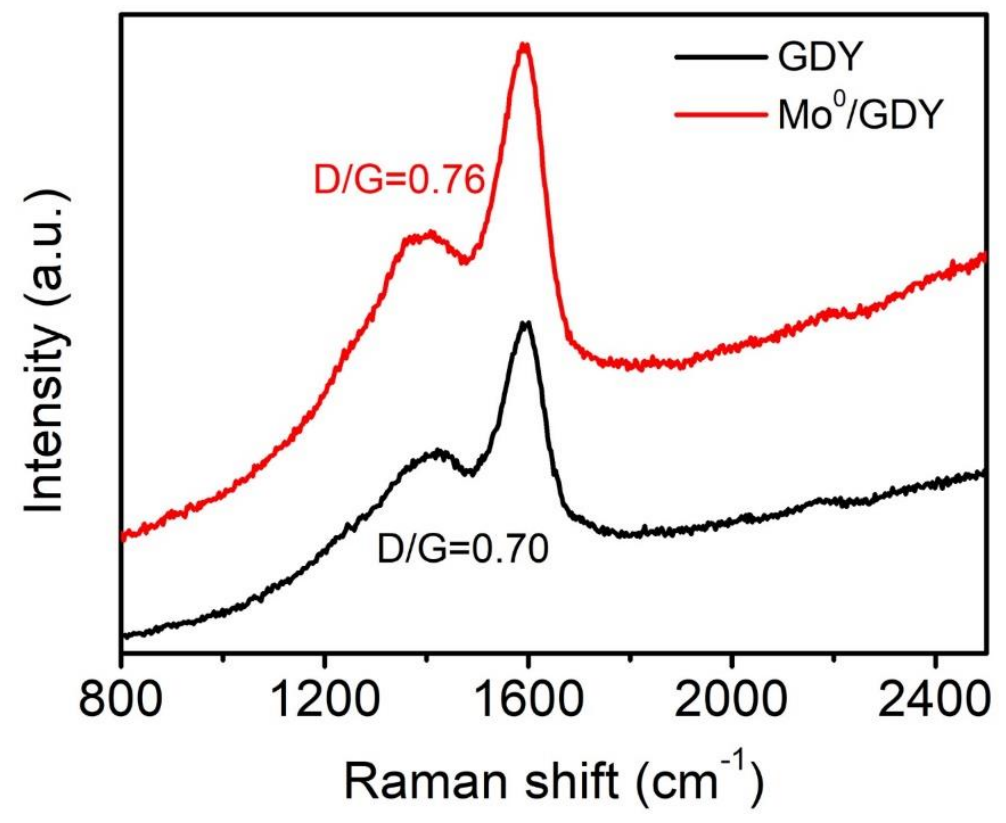

Figure S10. Raman spectra of pure GDY (black line) and $\mathrm{Mo}^{\circ} / \mathrm{GDY}$ (red line). The intensity ratio of $\mathrm{D}$ band to $\mathrm{G}$ band increased, from 0.70 to 0.76 , after the anchoring of Mo atoms on GDY, suggesting the formation of more defective sites. 


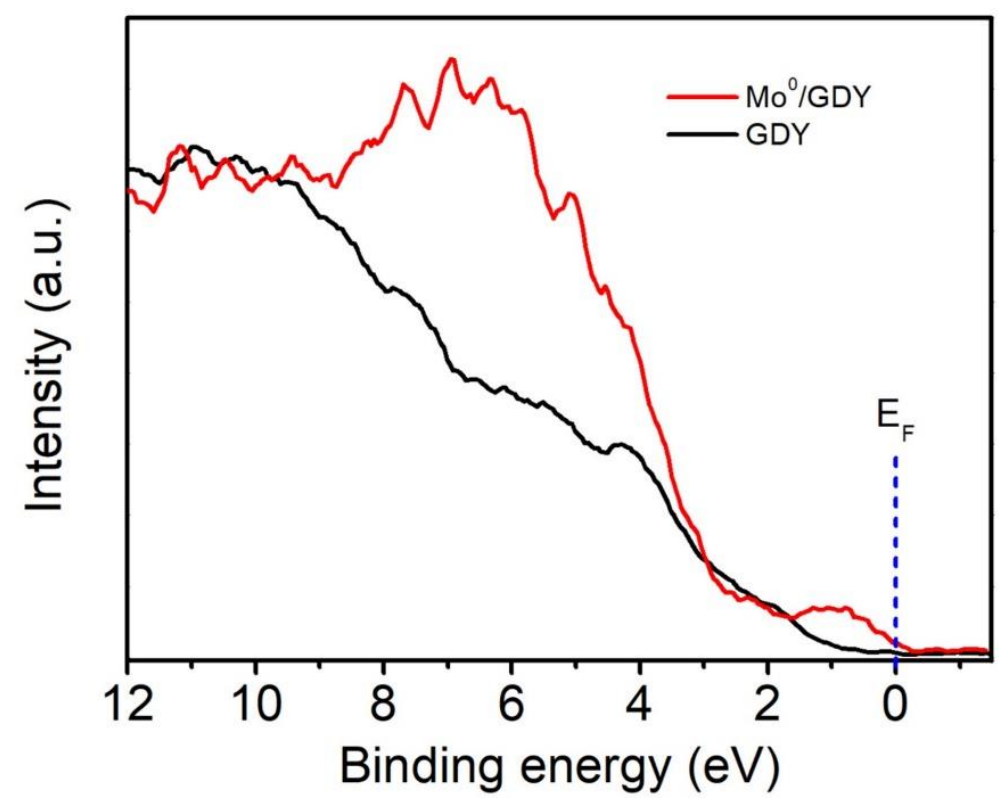

Figure S11. Valence-band spectra of $\mathrm{Mo}^{0} / \mathrm{GDY}$ and GDY. The top of the valence-band (TVB) of $\mathrm{Mo}^{0} / \mathrm{GDY}$ is more close to Fermi level compared with pristine GDY, which reveals its high electrical conductivity. 

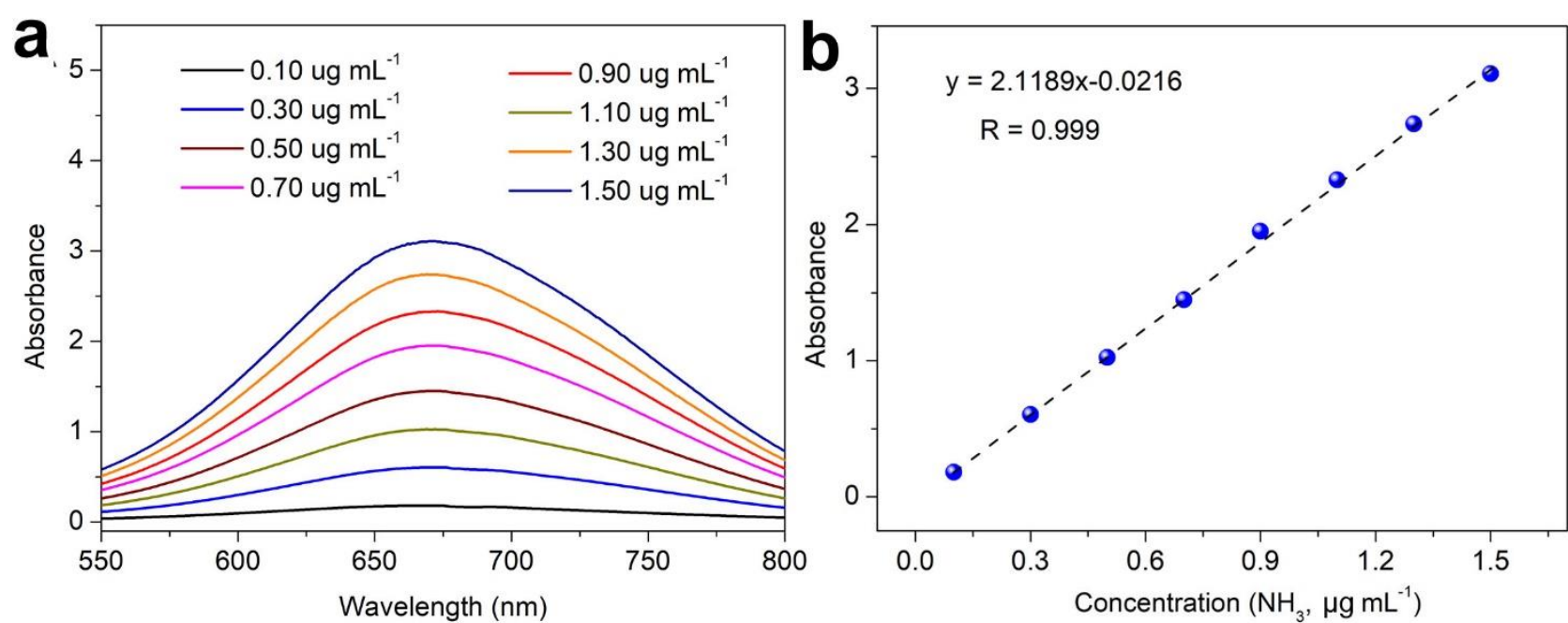

Figure S12. Determination of $\mathrm{NH} 3$ in $0.1 \mathrm{M} \mathrm{Na}_{2} \mathrm{SO}_{4}$. (A) UV-Vis absorption spectra of indophenol assays with standard $\mathrm{NH}_{3}$ solution after incubated for $1 \mathrm{~h}$ at room temperature. (b) Corresponding calibration curve. 


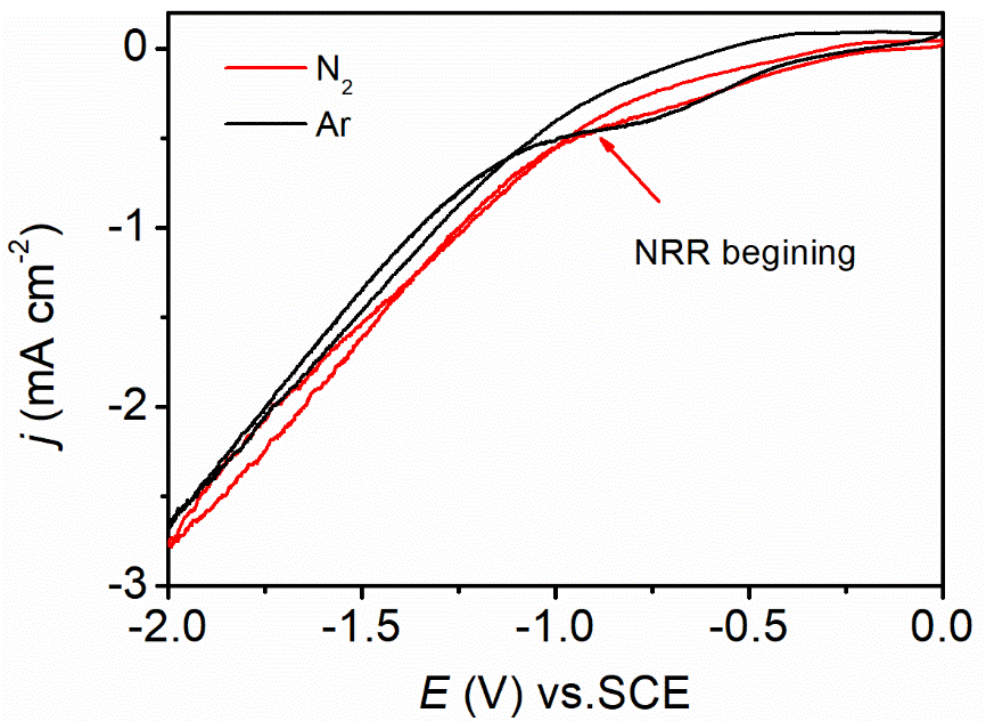

Figure S13. Cyclic voltammetry $(\mathrm{CV})$ curves of $\mathrm{Mo}^{0} / \mathrm{GDY}$ in $\mathrm{N}_{2}$-and Ar-saturated $0.1 \mathrm{M} \mathrm{Na}_{2} \mathrm{SO}_{4}$. 
a ECNRR in ${ }^{15} \mathrm{~N}_{2}$ saturated $0.1 \mathrm{M} \mathrm{Na}_{2} \mathrm{SO}_{4}$

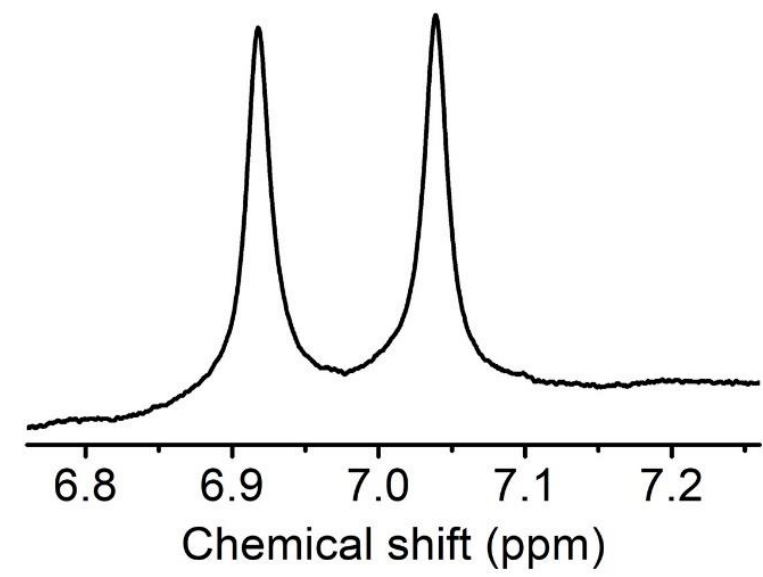

b

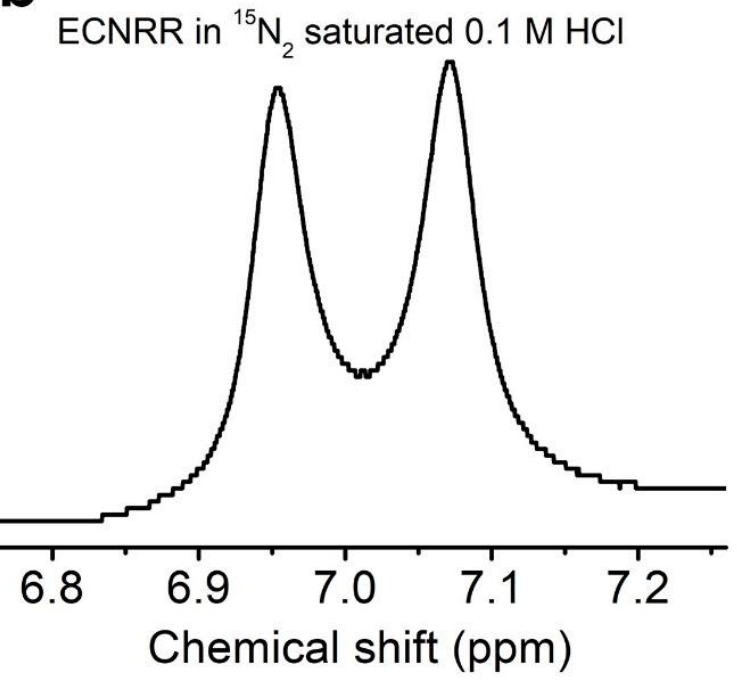

Figure S14. Isotope labeling experiments. ${ }^{1} \mathrm{H}$ NMR spectra of ammonium obtained after ECNRR in the presence of ${ }^{15} \mathrm{~N}_{2}$ saturated (a) $0.1 \mathrm{M} \mathrm{Na}_{2} \mathrm{SO}_{4}$ and (b) $0.1 \mathrm{M} \mathrm{HCl}$ electrolytes. 


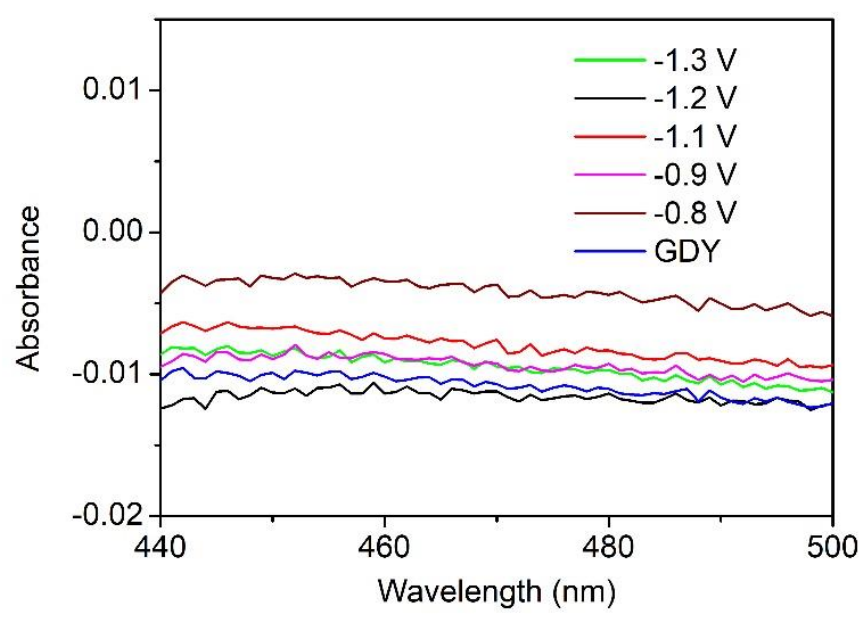

Figure S15. Detection of $\mathrm{N}_{2} \mathrm{H}_{4}$ after ECNRR in $0.1 \mathrm{M} \mathrm{Na}_{2} \mathrm{SO}_{4}$. 

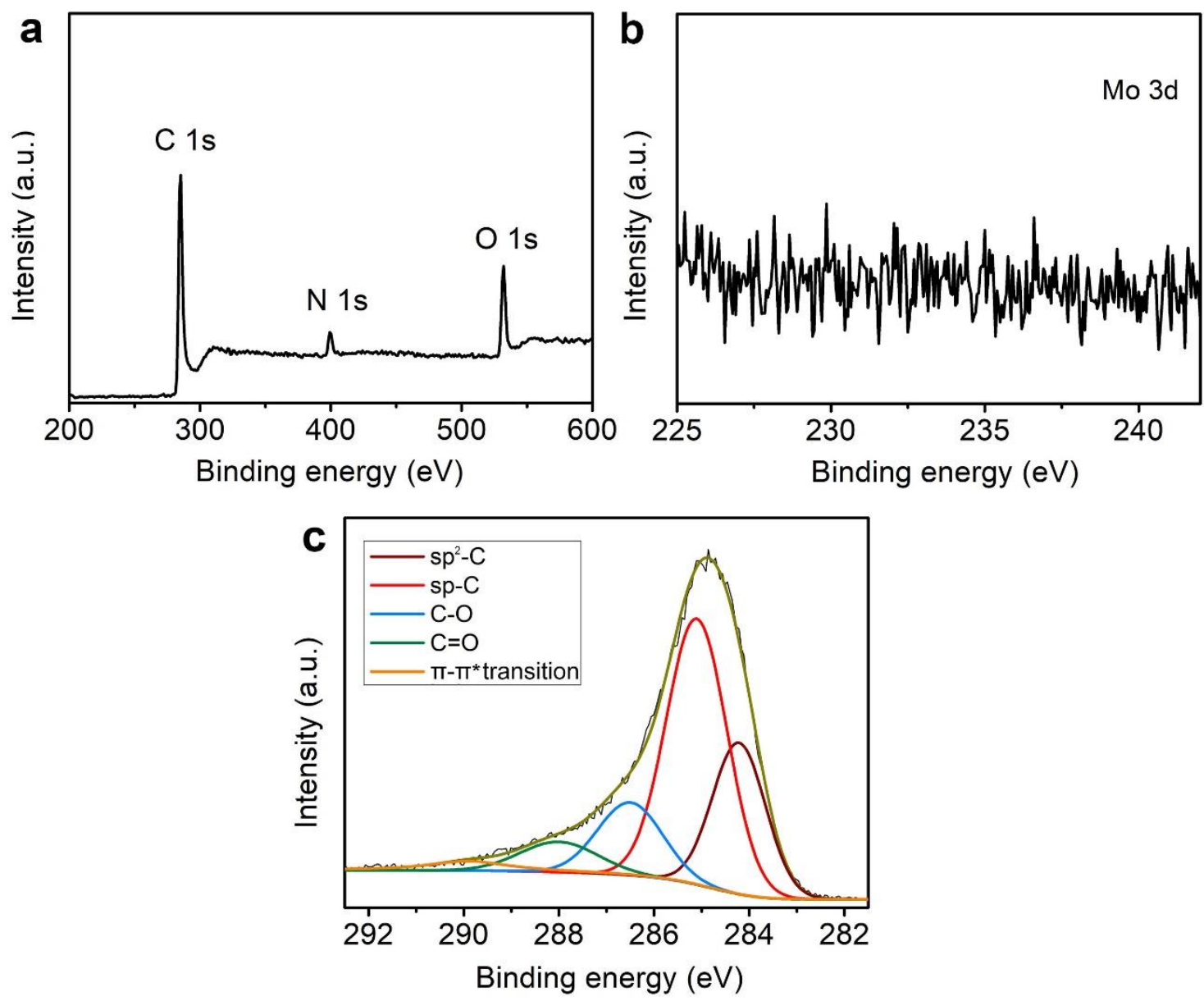

Figure S16. The survey spectrum (a) and high-resolution XPS spectra of the Mo 3d (b) and C1s (c) of the $\mathrm{Mo}^{\%} / \mathrm{GDY}$ after ECNRR measurements in $0.1 \mathrm{M} \mathrm{Na}_{2} \mathrm{SO}_{4}$. The peaks in $\mathrm{C} 1 \mathrm{~s}$ spectrum at 284.2, 285.0, 286.5, 288.0 and $289.9 \mathrm{eV}$ corresponds to the $\mathrm{sp}^{2}-\mathrm{C}, \mathrm{sp}-\mathrm{C}, \mathrm{C}=\mathrm{O}, \mathrm{C}=\mathrm{O}$ and $\pi-\pi^{*}$ transition, respectively. 

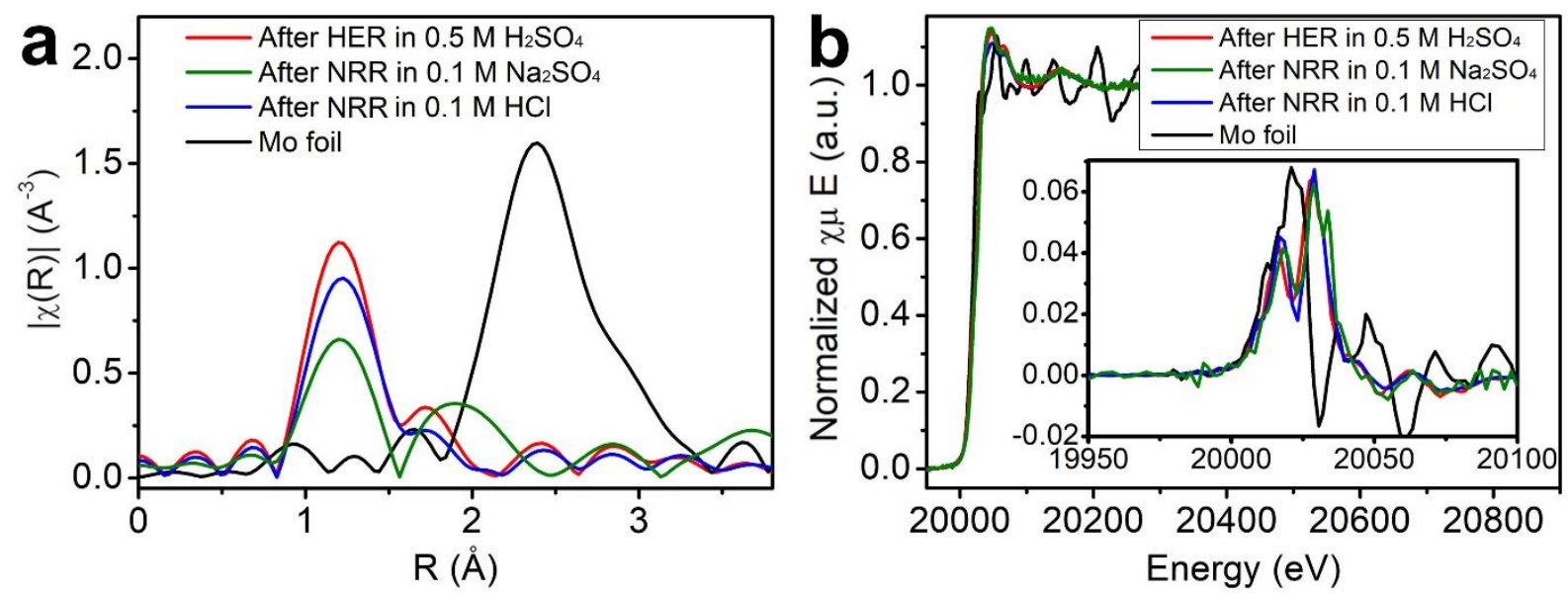

Figure S17. XAS studies of Mo\% GDY catalysts after electrochemical testing. (a) EXAFS spectra and (b) the normalized XANES spectra and first derivative curves (the inset) of $\mathrm{Mo}^{0} / \mathrm{GDY}$ catalysts obtained after HER test in $0.5 \mathrm{M} \mathrm{H}_{2} \mathrm{SO}_{4}$ (red line), ECRR test in $0.1 \mathrm{M} \mathrm{Na}_{2} \mathrm{SO}_{4}$ (green line) and 0.1 $\mathrm{M} \mathrm{HCl}$ (blue line) conditions. Mo foil was measured for comparison.

It is almost no difference in XANES and EXAFS spectra before and after electrochemical testing for $\mathrm{Mo}^{0} / \mathrm{GDY}$. The EXAFS spectra (Figure S17a) of the Mo\% GDY exhibits only one prominent peak centered around 1.2 $\AA$, and no peak corresponds to the Mo-Mo contribution $(\sim 2.4 \AA)$, indicating the only existence of the atomically dispersed Mo atoms after electrochemical measurements. The preedge derivative of XANES spectra of $M 0^{0} / G D Y$ could provide more information about the metal's covalence state while comparing with Mo foil. From Figure S17b, we find the entire XANES spectra of $\mathrm{Mo}^{0} / \mathrm{GDY}$ and Mo reference are almost same, and the pre-edge derivative of XANES of $\mathrm{Mo}^{0} / \mathrm{GDY}$ catalysts are similar to that of metallic Mo, confirming the zero-valence state of the Mo atoms after HER and ECNRR measurements. 

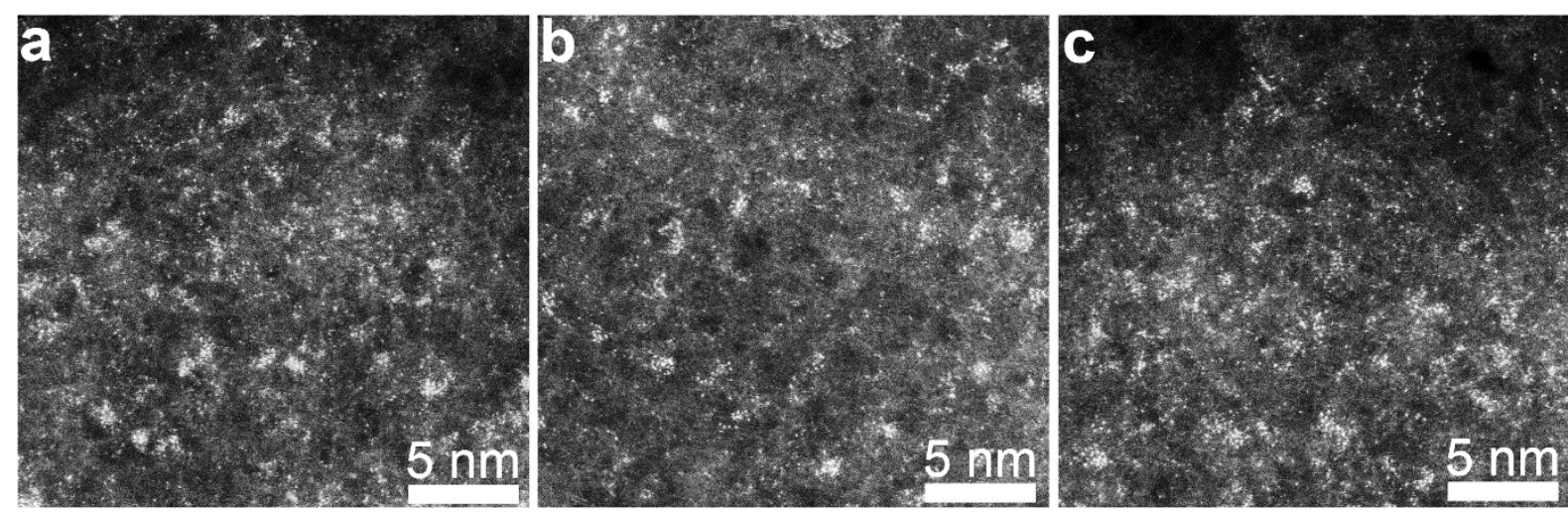

Figure S18. (a-c) HAADF-STEM images of $\mathrm{Mo}^{0} / \mathrm{GDY}$ samples obtained after ECNRR test in $0.1 \mathrm{M}$ $\mathrm{Na}_{2} \mathrm{SO}_{4}$. 


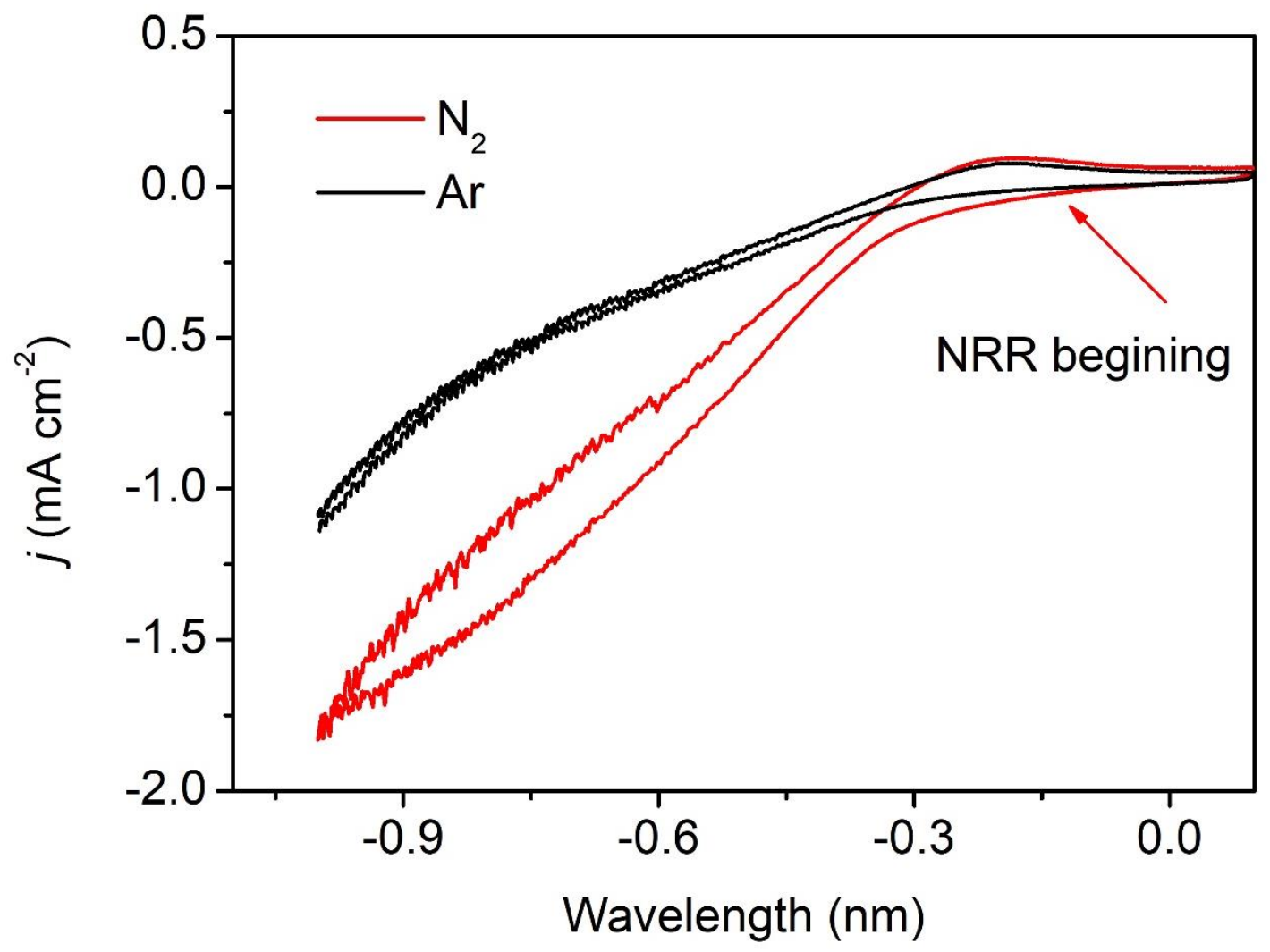

Figure S19. Cyclic voltammetry (CV) curves of $\mathrm{Mo}^{0} / \mathrm{GDY}$ in $\mathrm{N}_{2}$-and Ar-saturated $0.1 \mathrm{M} \mathrm{HCl}$. 

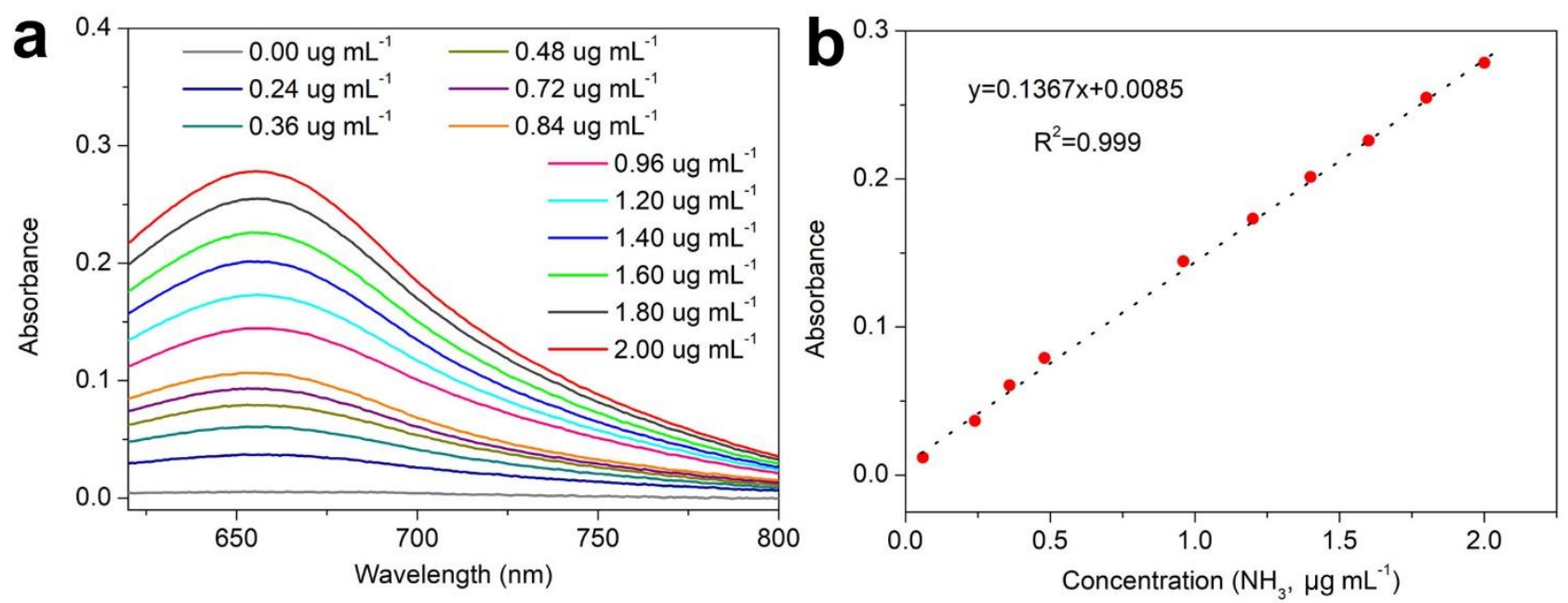

Figure S20. Determination of $\mathrm{NH}_{3}$ in $0.1 \mathrm{M} \mathrm{HCl}$. (a) UV-Vis absorption spectra of indophenol assays with standard $\mathrm{NH}_{3}$ solution after incubated for $1 \mathrm{~h}$ at room temperature. (b) Corresponding calibration curve. 


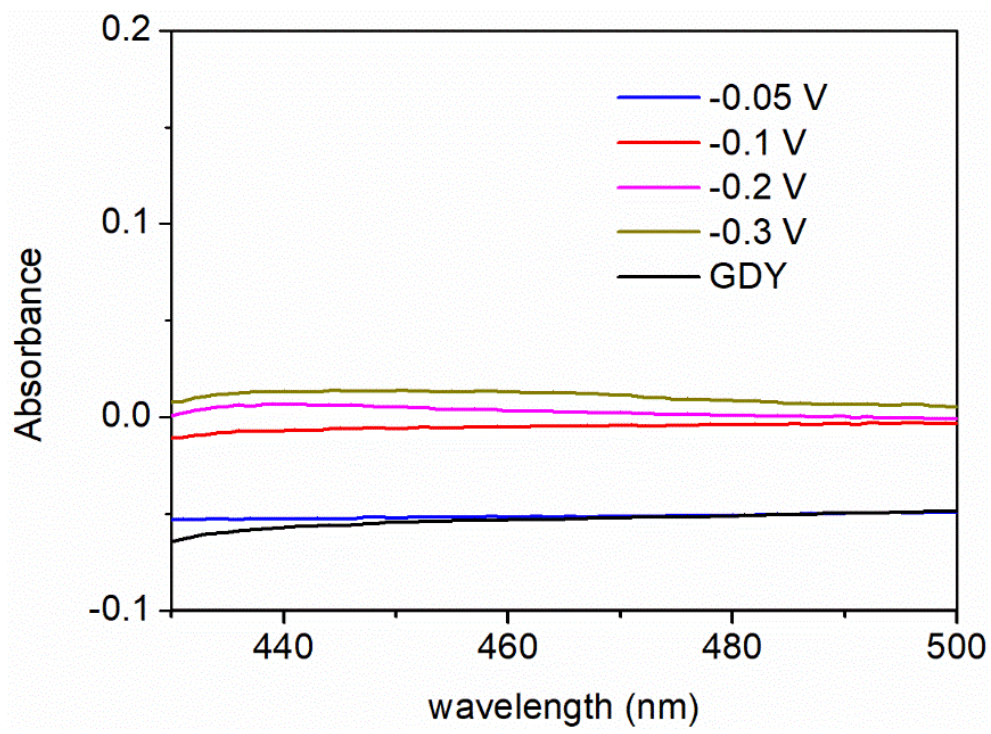

Figure S21. Determination of $\mathrm{N}_{2} \mathrm{H}_{4}$ after ECNRR in $0.1 \mathrm{M} \mathrm{HCl}$. 


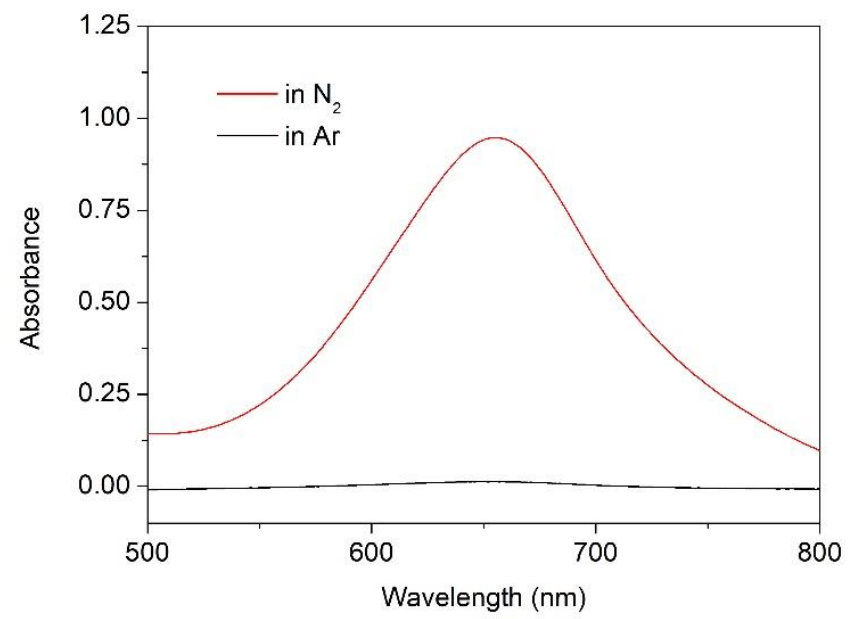

Figure S22. Detection of $\mathrm{NH}_{3}$ after ECNRR in $\mathrm{N}_{2}$-and Ar-saturated $0.1 \mathrm{M} \mathrm{HCl}$. 


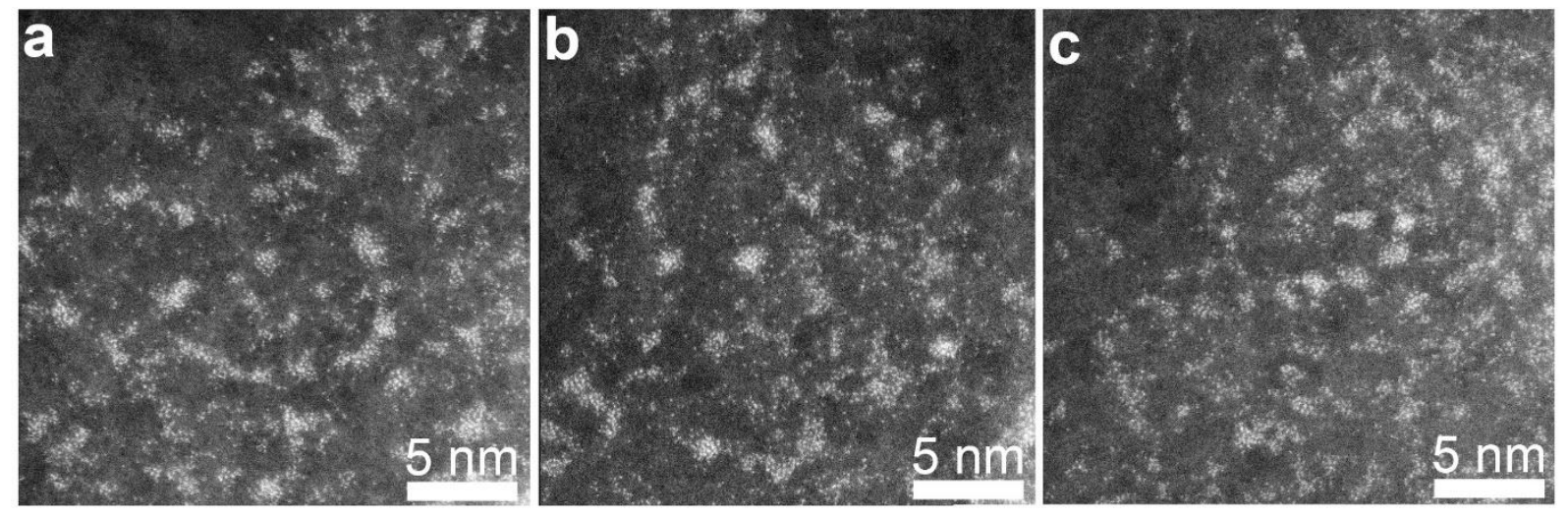

Figure S23. (a-c) HAADF-STEM images of $\mathrm{Mo}^{\circ} / \mathrm{GDY}$ samples obtained after ECNRR tests in 0.1 $\mathrm{M} \mathrm{HCl}$. 

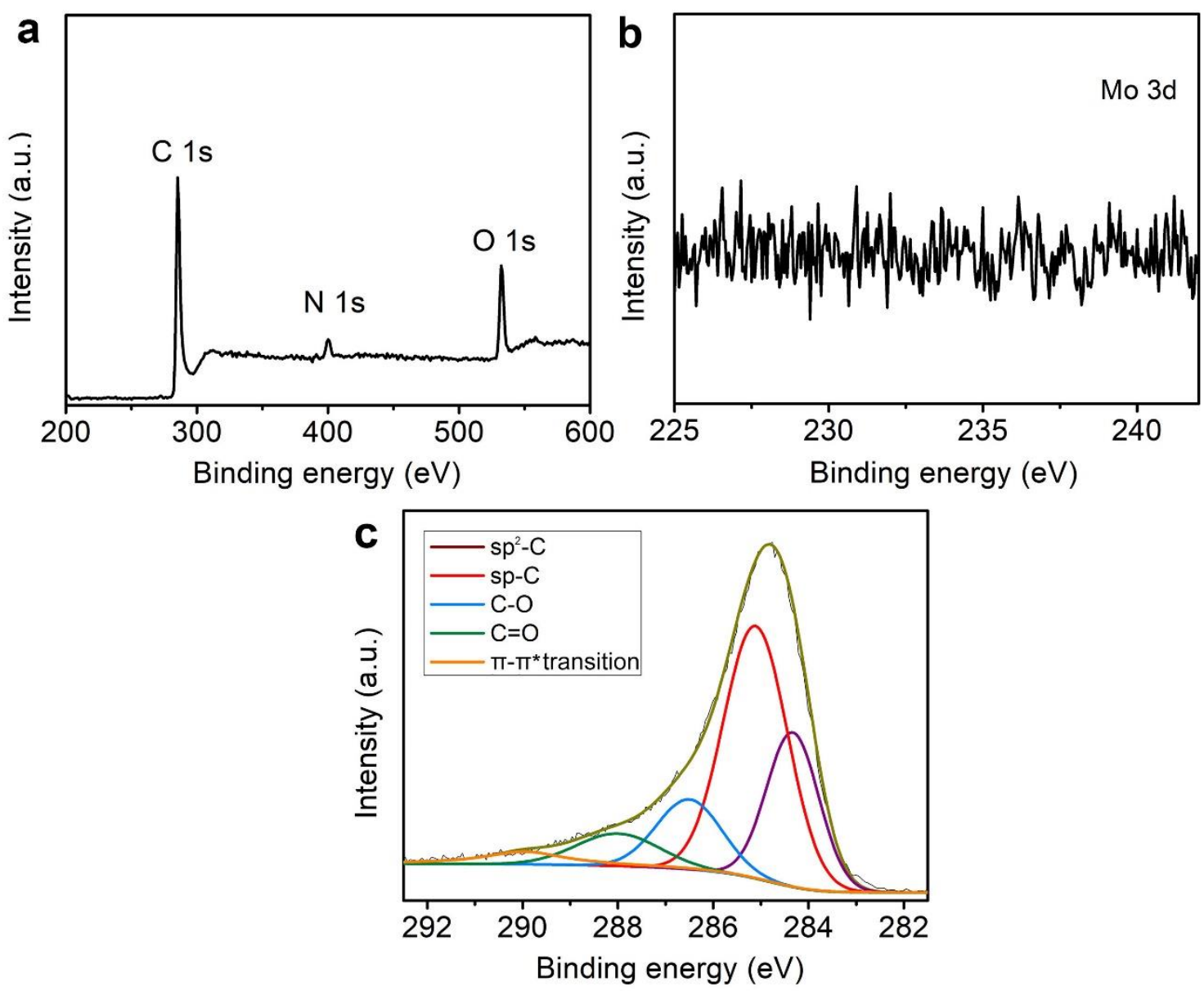

Figure S24. The survey spectrum (a) and high-resolution XPS spectra of the Mo 3d (b) and C1s (c) of the $\mathrm{Mo}^{0} / \mathrm{GDY}$ after ECNRR measurements in $0.1 \mathrm{M} \mathrm{HCl}$. The peaks in $\mathrm{C} 1 \mathrm{~s}$ spectrum at 284.4, 285.1, 286.5, 288.0 and $290.0 \mathrm{eV}$ corresponds to the $\mathrm{sp}^{2}-\mathrm{C}, \mathrm{sp}-\mathrm{C}, \mathrm{C}=\mathrm{O}, \mathrm{C}=\mathrm{O}$ and $\pi-\pi^{*}$ transition, respectively. 


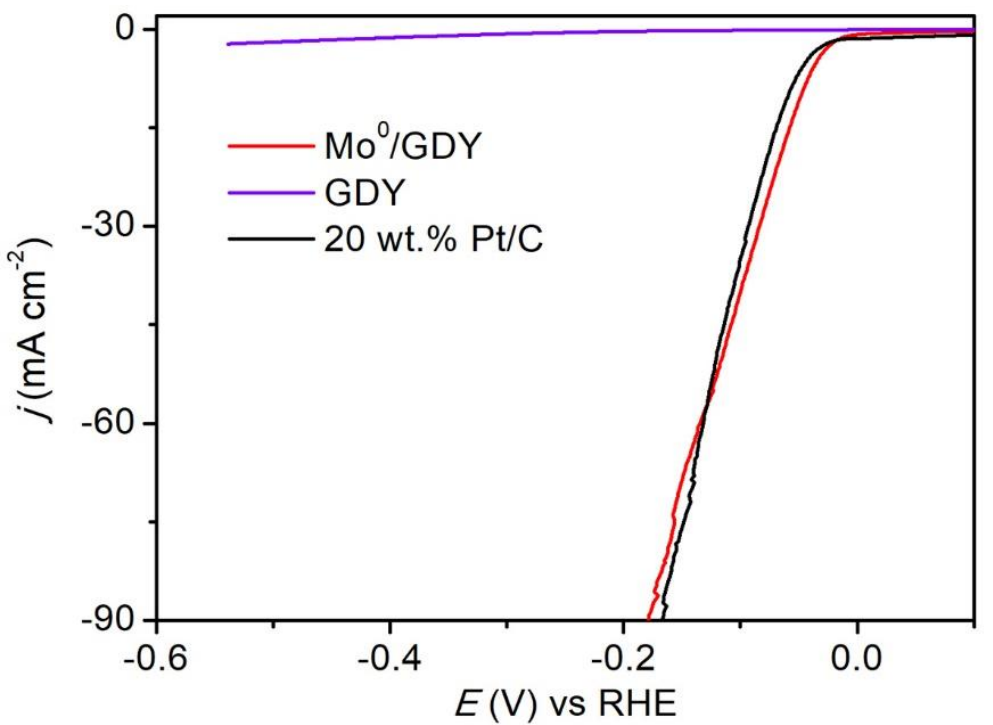

Figure S25. Polarization curves of $\mathrm{Mo}^{0} / \mathrm{GDY}$, pristine GDY, and $20 \mathrm{wt} \% \mathrm{Pt} / \mathrm{C}$. 


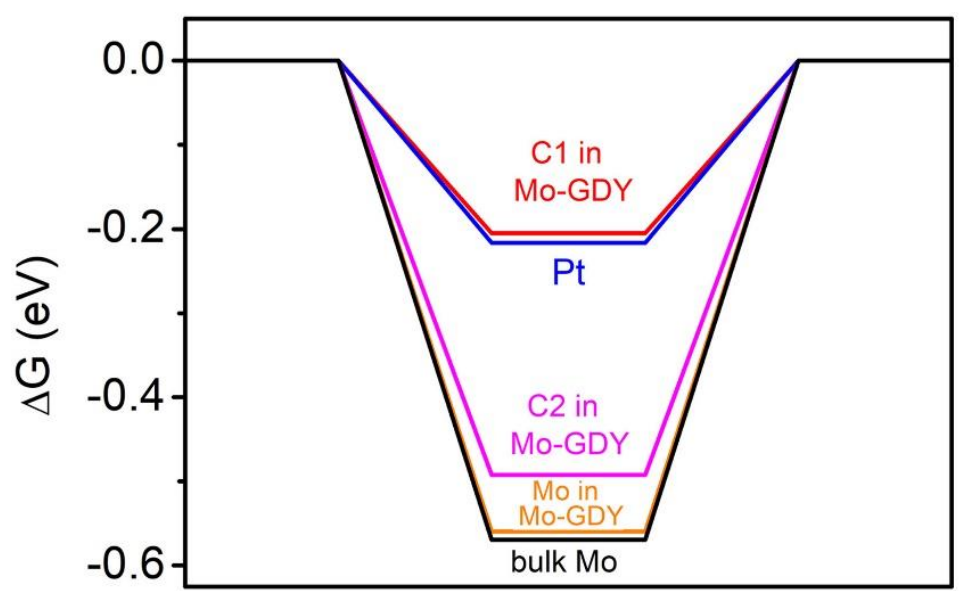

Figure S26. Hydrogen absorption free energy of the catalysts according to DFT calculation. 


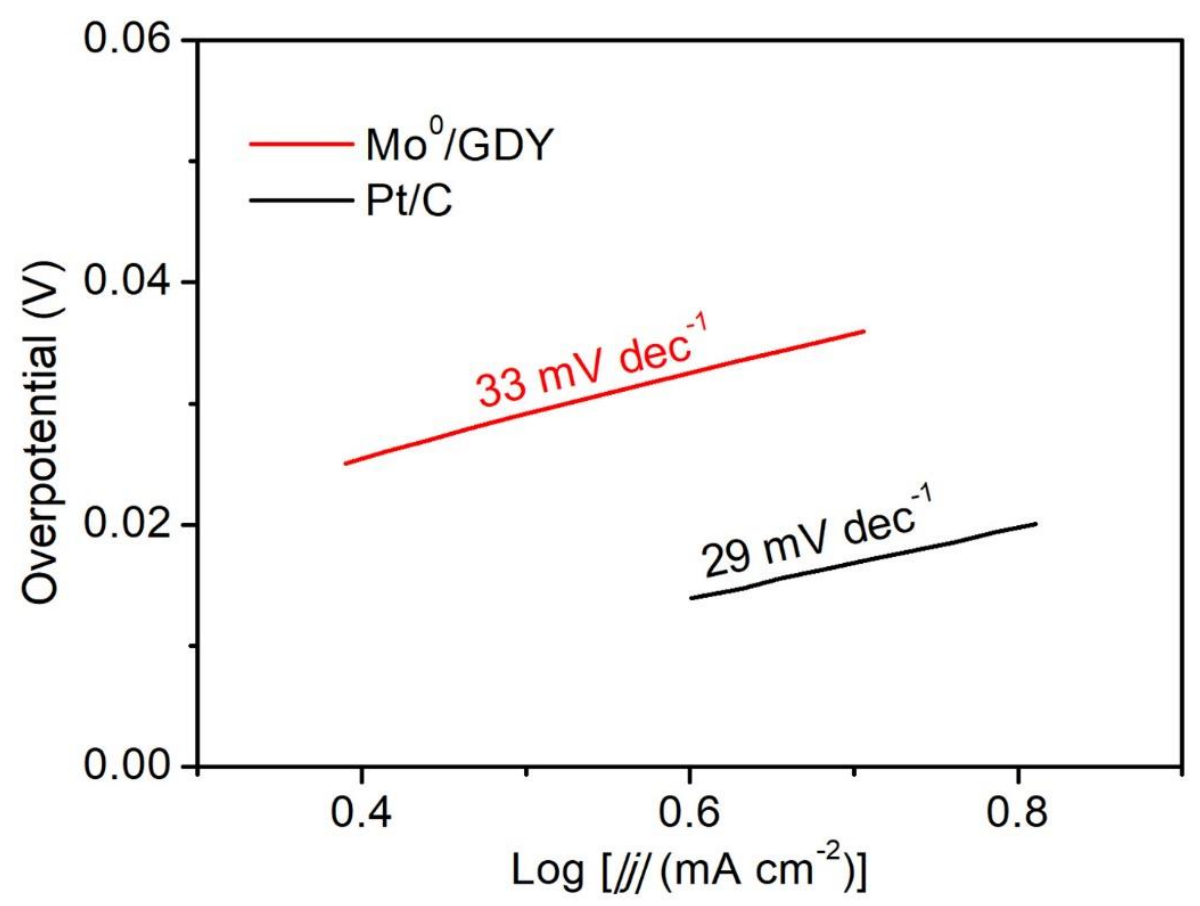

Figure S27. Tafel plots of the Mo $/ \mathrm{GDY}$ and $20 \mathrm{wt} . \% \mathrm{Pt} / \mathrm{C}$. 

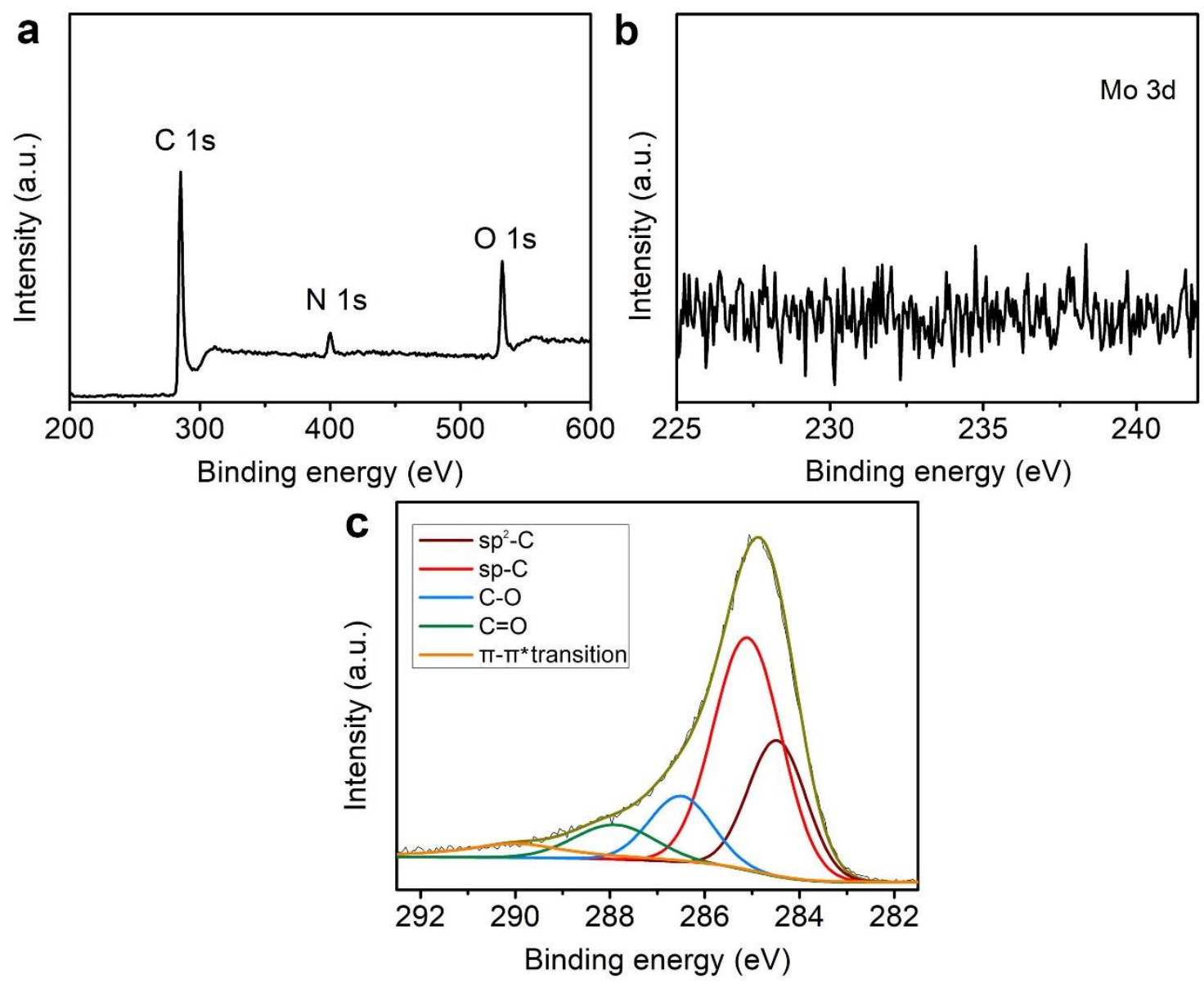

Figure S28. The survey spectrum (a) and high-resolution XPS spectra of the Mo 3d (b) and C1s (c) of the $\mathrm{Mo}^{0} / \mathrm{GDY}$ after HER measurements. The peaks in C 1s spectrum at 284.5, 285.1, 286.5, 287.9 and $290.0 \mathrm{eV}$ corresponds to the $\mathrm{sp}^{2}-\mathrm{C}, \mathrm{sp}-\mathrm{C}, \mathrm{C}=\mathrm{O}, \mathrm{C}=\mathrm{O}$ and $\pi-\pi^{*}$ transition, respectively. 

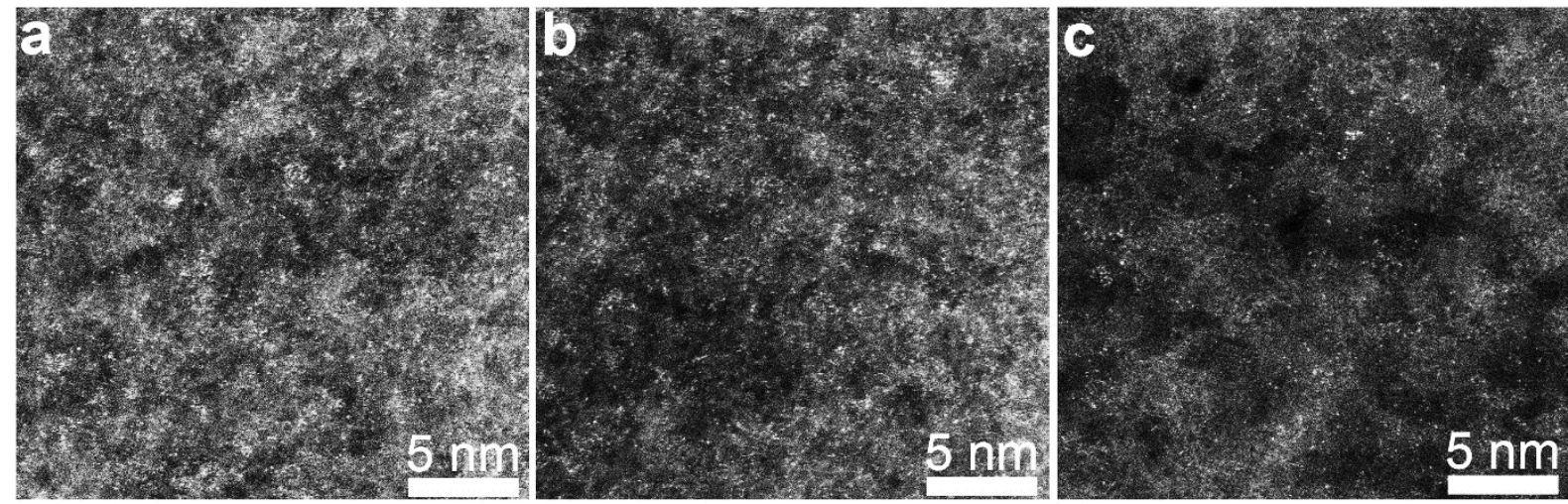

Figure S29. (a-c) HAADF-STEM images of $\mathrm{Mo}^{0} / \mathrm{GDY}$ samples obtained after HER tests in $0.5 \mathrm{M}$ $\mathrm{H}_{2} \mathrm{SO}_{4}$.

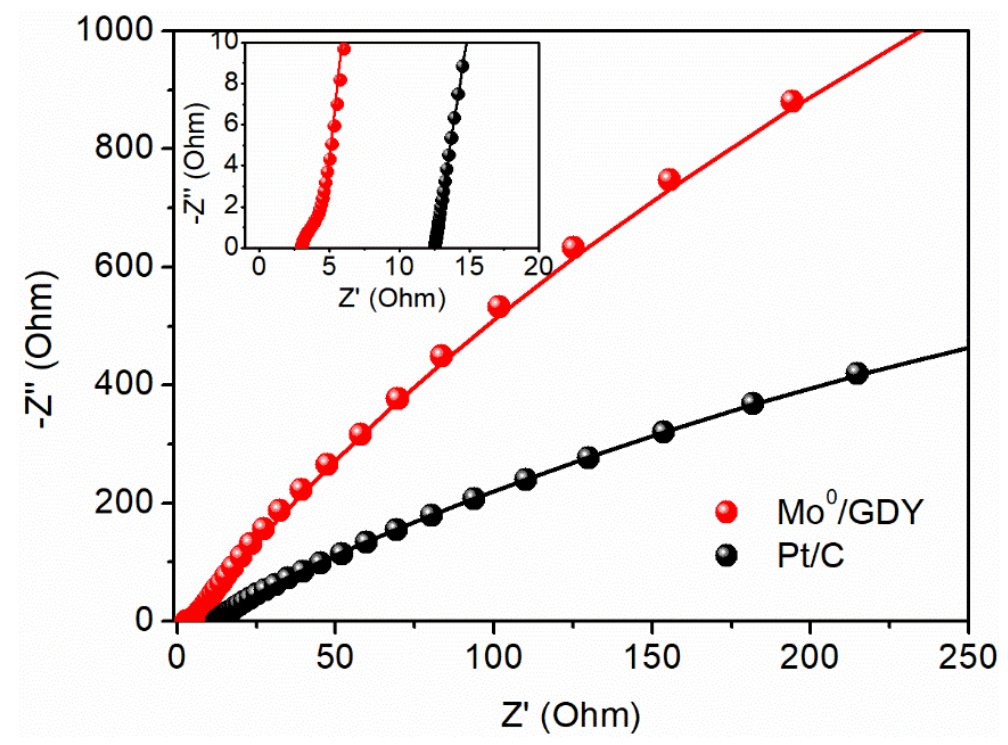

Figure S30. Nyquist plots of $\mathrm{Mo}^{0} / \mathrm{GDY}$ and $\mathrm{Pt} / \mathrm{C}$. The solid spheres represent the experimental EIS data; the solid lines with corresponding color are the fitting results from $R(Q R)(Q R)$ equivalent circuit model. 

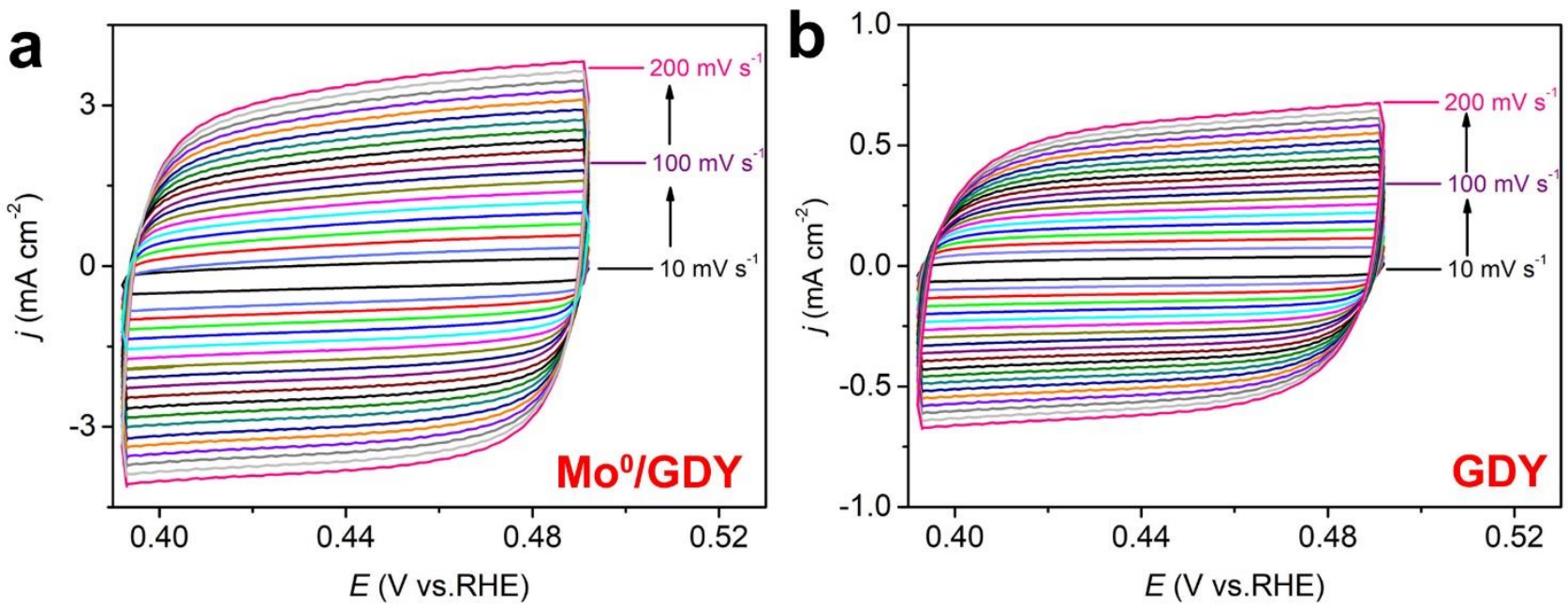

Figure S31. CV curves of a, Mo ${ }^{0} / G D Y$ and $b$, GDY for $C_{d l}$ measurement. 


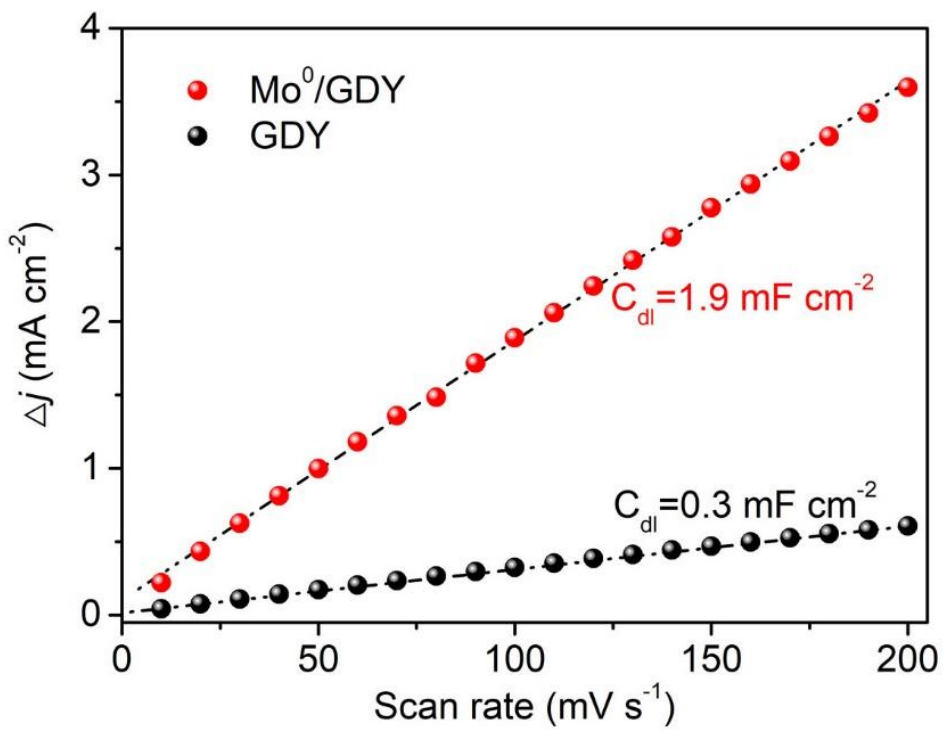

Figure S32. $\mathrm{C}_{\mathrm{dl}}$ measurement of $\mathrm{Mo}^{0} / \mathrm{GDY}$ and GDY. 
Table S1. ECNRR performances of Mo/GDY and other recently-reported catalysts.

\begin{tabular}{|c|c|c|c|c|}
\hline Ctalysts & Electrolytes & $\begin{array}{l}\mathbf{Y}_{\mathrm{NH3}}\left(\mu \mathbf{g}_{\mathrm{NH3}}\right. \\
\mathbf{m g}_{\left.\text {cat. }^{-1} \mathbf{h}^{-1}\right)}\end{array}$ & FE (\%) & References \\
\hline \multirow[t]{2}{*}{$\mathrm{Mo}^{0} / \mathrm{GDY}$} & $\begin{array}{c}0.1 \mathrm{M} \\
\mathrm{Na}_{2} \mathrm{SO}_{4}\end{array}$ & 145.4 & 21.0 & \multirow[t]{2}{*}{ This work } \\
\hline & $0.1 \mathrm{M} \mathrm{HCl}$ & 2000 & 15.6 & \\
\hline $\mathrm{a}-\mathrm{Au} / \mathrm{CeO}_{\mathrm{x}}-\mathrm{RGO}$ & $\begin{array}{c}\mathrm{pH}=1 \mathrm{HCl} \\
\text { solution }\end{array}$ & 8.3 & 10.10 & $\begin{array}{l}\text { Adv. Mater., 2017, 29, } \\
1700001\end{array}$ \\
\hline $\mathrm{Au} / \mathrm{TiO}_{2}$ & $\begin{array}{c}\mathrm{pH}=1 \mathrm{HCl} \\
\text { solution }\end{array}$ & 21.4 & 8.11 & $\begin{array}{l}\text { Adv. Mater., 2017, } 29 \\
1606550\end{array}$ \\
\hline $\mathrm{Bi}_{4} \mathrm{~V}_{2} \mathrm{O}_{11} / \mathrm{CeO}_{2}$ & $0.1 \mathrm{M} \mathrm{HCl}$ & 23.21 & 10.16 & $\begin{array}{l}\text { Angew. Chem. Int. Ed., } \\
\text { 2018, } 130,1-5\end{array}$ \\
\hline $\begin{array}{c}\text { polymeric carbon } \\
\text { nitride }\end{array}$ & $0.1 \mathrm{M} \mathrm{HCl}$ & 8.08 & 11.59 & $\begin{array}{l}\text { Angew. Chem. Int. Ed., } \\
\text { 2018, } 57,10246- \\
10250\end{array}$ \\
\hline $\mathrm{Pd}_{0.2} \mathrm{Cu}_{0.8} / \mathrm{rGO}$ & $0.1 \mathrm{M} \mathrm{KOH}$ & 1.66 & 4.5 & $\begin{array}{l}\text { Adv. Energy Mater., } \\
\text { 2018, } 8,1800124\end{array}$ \\
\hline $\mathrm{MoS}_{2}$ Nanoflower & $\begin{array}{c}0.1 \mathrm{M} \\
\mathrm{Na}_{2} \mathrm{SO}_{4}\end{array}$ & 29.28 & 8.34 & $\begin{array}{l}\text { Adv. Energy Mater., } \\
\mathbf{2 0 1 8}, 8,1801357\end{array}$ \\
\hline \multirow{2}{*}{$\mathrm{B}_{4} \mathrm{C} / \mathrm{CPE}$} & $0.1 \mathrm{M} \mathrm{HCl}$ & 26.57 & 15.95 & \multirow{2}{*}{$\begin{array}{l}\text { Nat. Commun., 2018, } \\
9,3485\end{array}$} \\
\hline & $\begin{array}{c}0.1 \mathrm{M} \\
\mathrm{Na}_{2} \mathrm{SO}_{4}\end{array}$ & 4.7 & 9.24 & \\
\hline
\end{tabular}


Table S2. EIS parameters of $\mathrm{Mo}^{\circ} / \mathrm{GDY}$ and GDY

\begin{tabular}{|c|c|c|}
\hline Catalysts & $\mathbf{M o}^{\mathbf{0}} / \mathbf{G D Y}$ & GDY \\
\hline $\mathrm{R}_{\mathrm{S}}(\Omega)$ & 3.14 & 12.57 \\
\hline $\mathrm{CPE}_{1} \mathrm{~S} \mathrm{sec}^{\mathrm{n}}$ & $6.715 \times 10^{-5}$ & $1.266 \times 10^{-3}$ \\
\hline $\begin{array}{c}\text { Freq power, } \mathrm{n}_{1} \\
(0<\mathrm{n}<1)\end{array}$ & 0.9766 & 0.8482 \\
\hline $\mathrm{R}_{\mathrm{ct}}(\Omega)$ & 1.299 & 42.68 \\
\hline $\mathrm{CPE}_{2} \mathrm{~S}$ sec $^{\mathrm{n}}$ & $2.483 \times 10^{-4}$ & $3.068 \times 10^{-4}$ \\
\hline $\begin{array}{c}\text { Freq power, } \mathrm{n}_{2} \\
(0<\mathrm{n}<1)\end{array}$ & 0.9086 & 0.8743 \\
\hline $\mathrm{R}_{1}(\Omega)$ & $1.233 \times 10^{4}$ & 25.88 \\
\hline
\end{tabular}




\section{References:}

(1) Clark, S. J.; Segall, M. D.; Pickard, C. J.; Hasnip, P. J.; Probert, M. I. J.; Refson, K.; Payne, M.

C. First Principles Methods Using CASTEP. zkri 2005, 220, 567.

(2) (a) Huang, B. Intrinsic Deep Hole Trap Levels in $\mathrm{Cu}_{2} \mathrm{O}$ With Self-Consistent Repulsive Coulomb Energy. Solid State Commun. 2016, 230, 49. (b) Huang, B. Strong Compensation Hinders the P-type Doping of ZnO: a Glance Over Surface Defect Levels. Solid State Commun. 2016, 237-238, 34. (c)

Huang, B. 4f Fine-structure Levels as the Dominant Error in The Electronic Structures of Binary Lanthanide Oxides. J. Comput. Chem. 2016, 37, 825. (d) Huang, B. The Screened Pseudo-Charge Repulsive Potential in Perturbed Orbitals for Band Calculations by DFT $+U$. Phys. Chem. Chem. Phys. 2017, 19, 8008 .

(3) Vladimir, I. A.; Aryasetiawan, F.; Lichtenstein, A. I. First-principles Calculations of the Electronic Structure and Spectra of Strongly Correlated Systems: The LDA+ U Method. J. Phys. Condens. Matter. 1997, 9, 767.

(4) Marzari, N.; Vanderbilt, D.; Payne, M. C. Ensemble Density-Functional Theory for Ab Initio Molecular Dynamics of Metals and Finite-Temperature Insulators. Phys. Rev. Lett. 1997, 79, 1337.

(5) Kleinman, L.; Bylander, D. M. Efficacious Form for Model Pseudopotentials. Phys. Rev. Lett. 1982, 48, 1425.

(6) Louie, S. G.; Froyen, S.; Cohen, M. L. Nonlinear Ionic Pseudopotentials In Spin-DensityFunctional Calculations. Phys. Rev. B 1982, 26, 1738.

(7) Grinberg, I.; Ramer, N. J.; Rappe, A. M. Transferable Relativistic Dirac-Slater Pseudopotentials. Phys. Rev. B 2000, 62, 2311.

(8) Rappe, A. M.; Rabe, K. M.; Kaxiras, E.; Joannopoulos, J. D. Optimized Pseudopotentials. Phys. Rev. B 1990, 41, 1227. 